OPEN ACCESS

Edited by:

Raphael Ritti-Dias,

Universidade Nove de Julho, Brazil

Reviewed by:

Daroonwan Suksom,

Chulalongkorn University, Thailand

Laurie Wideman,

University of North Carolina at Greensboro, United States

${ }^{*}$ Correspondence:

Mikel Izquierdo

mikel.izquierdo@gmail.com

Specialty section:

This article was submitted to

Virology,

a section of the journal

Frontiers in Microbiology

Received: 17 August 2021

Accepted: 15 October 2021

Published: 11 November 2021

Citation:

Alvarez C, Ciolac EG, Guimarães GV,

Andrade DC, Vasquez-Muñoz $M$,

Monsalves-Álvarez $M$,

Delgado-Floody P,

Alonso-Martínez AM and

Izquierdo M (2021) Residual Impact of Concurrent, Resistance, and High-

Intensity Interval Training on Fasting Measures of Glucose Metabolism in Women With Insulin Resistance.

Front. Physiol. 12:760206. doi: 10.3389/fphys.2021.760206

\section{Residual Impact of Concurrent, Resistance, and High-Intensity Interval Training on Fasting Measures of Glucose Metabolism in Women With Insulin Resistance}

\author{
Cristian Alvarez ${ }^{1}$ Emmanuel Gomes Ciolac', Guilherme Veiga Guimarães ${ }^{3}$, \\ David C Andrade ${ }^{4}$, Manuel Vasquez-Muñoz ${ }^{5}$, Matías Monsalves-Álvarez ${ }^{6,7}$, Pedro Delgado- \\ Floody $^{8}$, Alicia M. Alonso-Martínez ${ }^{9}$ and Mikel Izquierdo, ${ }^{9,10 *}$
}

${ }^{1}$ Quality of Life and Wellness Research Group, Department of Health, Universidad de Los Lagos, Osorno, Chile, ${ }^{2}$ Exercise and Chronic Disease Research Laboratory, Department of Physical Education, School of Sciences, São Paulo State University (UNESP), São Paulo, Brazil, ${ }^{3}$ Heart Institute, School of Medicine, University of São Paulo, São Paulo, Brazil, ${ }^{4}$ Centro de Investigación en Fisiología y Medicina de Altura (FiMedAlt), Biomedical Department, Facultad de Ciencias de la Salud, Universidad de Antofagasta, Antofagasta, Chile, ${ }^{5}$ Clinica Santa Maria, Santiago, Chile, ${ }^{6}$ Instituto de Ciencias de La Salud, Universidad de O'higgins, Rancagua, Chile, ${ }^{7}$ Human Performance Laboratory, Motion Health and Performance Center, Lo Barnechea, Chile, ${ }^{8}$ Department of Physical Education, Sports and Recreation, Universidad de La Frontera, Temuco, Chile, ${ }^{9}$ Navarrabiomed, Hospital Universitario de Navarra (HUN), Universidad Pública de Navarra (UPNA), IdiSNA, Pamplona, Spain, ${ }^{10} \mathrm{CIBER}$ of Frailty and Healthy Aging (CIBERFES), Instituto de Salud Carlos III, Madrid, Spain

We sought to assess the residual effects (post 72-h training cessation) on fasting plasma glucose (FPG) and fasting insulin (FI) after 12-weeks of high-intensity interval training $(H I I T)$, resistance training $(R T)$, or concurrent training $(C T)$ in women with insulin resistance $(\mathrm{IR})$. We also aimed to determine the training-induced, post-training residual impact of CT. A total of adult 45 women (age $38.5 \pm 9.2$ years) were included in the final analysis and were assigned to a control (CG; $n=13$, BMI $\left.28.3 \pm 3.6 \mathrm{~kg} / \mathrm{m}^{2}\right)$, HIIT $\left[n=14\right.$, BMl $28.6 \pm 3.6 \mathrm{~kg} / \mathrm{m}^{2}$, three sessions $/ \mathrm{wk}$., $80-100 \%$ of the maximum heart rate $\left.\left(H R_{\max }\right)\right], R T\left[n=8, B M l 29.4 \pm 5.5 \mathrm{~kg} / \mathrm{m}^{2}\right.$, two sessions $/ w k ., 8-10$ points of the modified Borg, corresponding to 20 to $50 \%$ range of one maximum repetition test (1RM)], or CT group ( $n=10$, BMl $29.1 \pm 3.0 \mathrm{~kg} / \mathrm{m}^{2}$, three sessions $/ \mathrm{wk} ., 80-100 \%$ of $\mathrm{HR}_{\max }$, and 8-10 Borg, or 20 to $50 \%$ range of $1 \mathrm{RM}$, to each HIIT and RT compounds), with the latter including both HIIT and RT regimens. Training interventions lasted 12-weeks. The main outcomes were FPG and FI measured at pre- and 24-h and 72-h post-training ( $\mathrm{FPG}_{24 \mathrm{~h}}, \mathrm{Fl}_{24 \mathrm{~h}}$, and $\mathrm{FPG}_{72 \mathrm{~h}}, \mathrm{Fl}_{72 \mathrm{~h}}$, respectively). Secondary endpoints were body composition/anthropometry and the adiposity markers waist circumference (WC) and tricípital skinfold $\left(\mathrm{T}_{\mathrm{SF}}\right)$. The residual effects 72 -h post-training [delta $(\Delta)$ ] were significantly poorer (all $p<0.01)$ in the CT group $\left(\Delta \mathrm{FPG}_{72 \mathrm{~h}}+6.6 \mathrm{mg} / \mathrm{dl}, \eta^{2}: 0.76\right)$ than in the HIIT $\left(\Delta \mathrm{FPG}_{72 \mathrm{~h}}+1.2 \mathrm{mg} / \mathrm{dl}, \eta^{2}: 0.07\right)$ and $\mathrm{RT}\left(\Delta \mathrm{FPG} \mathrm{G}_{72 \mathrm{~h}}+1.0 \mathrm{mg} / \mathrm{dl}, \eta^{2}: 0.05\right)$ groups. These findings reveal that HIIT reduces FPG and RT reduces FI 24-h posttraining; both exercise interventions alone have remarkably better residual effects on FPG and FI (post-72 h) than CT in women with insulin resistance.

Keywords: insulin resistance, resistance training, high-intensity interval training, concurrent training, metabolism 


\section{INTRODUCTION}

Insulin resistance (IR) is the inability of the insulin hormone to facilitate glucose uptake from peripheral tissues to meet metabolic demands (Abdul-Ghani and DeFronzo, 2010). IR precedes type 2 diabetes mellitus (T2DM; Abdul-Ghani and DeFronzo, 2010) and is a hallmark of the disease. In 2017, the overall public spending on T2DM reached \$ 237 billion in the United States alone (Wang et al., 2017). Among the different available therapies to treat $\mathrm{T} 2 \mathrm{DM}$ and its complications, exercise training is a unique, non-pharmacological intervention that improves several physical inactivity-related metabolic disorders including IR (Jenkins and Hagberg, 2011; Slentz et al., 2011; Matos et al., 2018) and is a therapy for T2DM (Little et al., 2018). The major beneficial metabolic effects of exercise training are associated with structural adaptations (i.e., changes to adipose, skeletal muscle, bone tissue, and vessels), and with residual effects (hours or days post-exercise) in at-risk populations (Andersen and Høstmark, 2007; Short et al., 2012; Burke et al., 2017).

It is well known that some training regimens can promote improvements in several cardiometabolic markers (American Diabetes Association, 2017). High-intensity interval training (HIIT) and resistance training (RT) have been recommended for people with poor glucose control (Hayes et al., 2009; Colberg et al., 2016; Colberg, 2017). HIIT promotes greater cardiorespiratory fitness (CRF) and metabolic benefits in populations IR (Jelleyman et al., 2015) and T2DM (Little et al., 2011). Additionally, RT also promotes similar glucose control improvements to HIIT (Ross et al., 2021), by increasing skeletal muscle (Brooks et al., 2007) and bone mass (Wood and O'Neill, 2012) in patients with T2DM (Dunstan et al., 2002; Ross et al., 2021). The combination of moderate-intensity continuous training (MICT) plus RT, or also as HIIT plus RT (Da Silva et al., 2020), resulting in a training regimen known as concurrent training (CT), has also relevant evidence in favor of IR patients (Timmons et al., 2018; Álvarez et al., 2019). Indeed, we recently reported beneficial cardiometabolic outcomes in women with hyperglycemia after a 20-week CT intervention, including $-4 \mathrm{mg} / \mathrm{dl}$ decreases in fasting plasma glucose (FPG), and other physiological adaptations in body composition $(-4 \mathrm{~cm}$ waist circumference, $+400 \mathrm{~g}$ increases in lean mass), cardiovascular system $(-6 /-3 \mathrm{mmHg}$ reduction in systolic/diastolic blood pressure), and plasma lipoproteins $(-11 \mathrm{mg} / \mathrm{dl}$ LDL-cholesterol reduction) and greater increases in endurance performance $(+56 \mathrm{~m}$ in the 6-min walking test; Álvarez et al., 2019). While numerous studies have reported improved cardiometabolic health after shortor long-term exercise training with HIIT, RT, or CT, these exercise adaptations are typically short-lived and are reversed after training cessation (detraining), as is the case for metabolic outcomes (Bajpeyi et al., 2009; Del Vecchio et al., 2020). At the level of physiological adaptations from HIIT, RT, and CT, the results are scarce at level of post-exercise cessation, and few studies, and few studies have monitored the residual effects on glucose control markers in IR cohorts (Short et al., 2012).

In the case of CT, some studies have reported "interference effects" when performing HIIT plus RT in the same exercise routine (Wilson et al., 2012; Vechin et al., 2021), while others have found no detrimental interactions in health-related and performance outcomes (Lundberg et al., 2013; Villareal et al., 2017). Specifically, the "interference effect" has been described when MICT, or RT alone promotes a specific molecular profile that generates mitochondrial biogenesis and thus increases fatigue tolerance or hypertrophy, and strength at the skeletal muscle level, but when both regimens are applied concurrently (in the same exercise session), other more specific training adaptations can occur, and endurance training can attenuate the muscle hypertrophy and strength gains (Coffey and Hawley, 2017). Some of the discrepancies in the literature likely arise because of the order of the sessions of CT [i.e., RT+HIIT or HIIT+RT (Bagheri et al., 2020)], or in the comparisons of CT vs. RT or HIIT alone, in which no differences were reported in strength performance increases, but minor cardiorespiratory adaptations are evident when comparing CT vs. MICT or RT alone (Glowacki et al., 2004). In addition, while HIIT has a strong capacity for improving CRF, and marked evidence for reducing adiposity impacting overall adiposity markers, by contrast, RT has a high capacity for increasing skeletal muscle mass and other tissues as bone.

It has been proposed that the beneficial adaptations to exercise training are not related to the training itself, where most of these are linked to the recovery period, or after exercise cessation, which is known as "residual effect." For example, most events in which glucose control is improved by exercise training (i.e., FPG decreases) are after exercise cessation, major body fat decreases operate similarly after HIIT, or the greater skeletal muscle mass increases are resulting from the sum of physiological events during recovery time. Thus, particularly, the residual effect is the post-exercise cessation time in which the beneficial exercise effects are extended without exercise participation until these physiological adaptations are lost, but at the same time other adaptations are assembled at different systems (tissues, cardiovascular, metabolic among others).

Based on previous reports about some detrimental adaptations to increase strength from CT of endurance plus RT exercise in which RT alone promote more strength increases (Bajpeyi et al., 2009), considering the relevance of increasing skeletal muscle mass for glucose control in IR and T2DM patients (Dunstan et al., 2002; Brooks et al., 2007; Ross et al., 2021), we hypothesized that both HIIT or RT alone, but not CT, would have long-term residual effects on FPG and FI in women with IR. Thus, the present study aimed to assess the residual effects (post-72-h training cessation) on FPG and FI after 12-weeks of HIIT, RT, or CT in adult women with IR.

\section{MATERIALS AND METHODS}

We studied physically inactive adult women with insulin resistance but with no diagnosis of T2DM. The study was performed in accordance with the ethical standards established by the Declaration of Helsinki (2013) and was approved by the local ethical committee of the Family Healthcare Center TRV of Los Lagos, Chile (no. 0204015). The study was not registered in a database. All participants signed a written informed consent.

Eligibility criteria included the following: (a) age between 25 and 60 years; (b) diagnosis of insulin resistance [homeostasis 
model assessment of insulin resistance (HOMA-IR) 2 2.6] (Garmendia et al., 2009); (c) to be physically inactive (i.e., a total of $<150 \mathrm{~min} /$ week of low-moderate physical activity or $<75 \mathrm{~min} /$ week of vigorous activity according to an International Physical Activity Questionnaire; O’Donovan et al., 2010); (d) to do not report exercise training participation the last 3 months; (e) family history of T2DM; (f) to live in urban areas (related to modern life); (g) absence of musculoskeletal disorders; (h) absence of bone inflammatory, ischemic, and/or cardiac diseases; (i) absence of asthma and/or chronic obstructive pulmonary disease; ( $j$ ) not to be under pharmacological treatment that modulates metabolic and/or respiratory control; and (k) free from hypertension and/or hypothyroidism diagnosis.

\section{Subjects}

After a public invitation from the Healthcare Center, 162 adult women were assessed for eligibility. A total of 82 individuals were excluded by: (a) age $>60$ years $(n=16)$, (b) reporting recent exercise participation $(n=2)$, (c) hypertension diagnosis $(n=5)$, (d) T2DM diagnosis $(n=5)$, (e) hypothyroidism diagnosis $(n=5)$, (f) musculoskeletal limitation $(n=3)$, (g) no family history of T2DM $(n=36)$, (h) stationary respiratory disease, such as asthma $(n=6)$, and (i) inability to adhere to exercise sessions due to living in rural areas $(n=4)$. Thus, from the 80 participants available, we extracted 5 that were randomly assigned 1:1 to control group (CG, $n=20$; HIIT, $n=20$; RT, $n=20$; and CT, $n=20$ ). Using a $\mathrm{G}^{*}$ Power 3.1.9.7 statistical sample size calculator, with an $\alpha$ error probability 0.05 , with $95 \%$ confidence interval (CI) for 4 groups, over three time points of measurements, and expecting mediumto-large effect sizes [(i.e., $\eta^{2}$ : from $\geq 0.06$ to $\geq 0.14$ ), a minimum of eight subjects per group would give a statistical power of $\geq 90 \%)$ ]. A minimum of $70 \%$ compliance, and no intermittent adherence (do not adhere up to 4 or more continuous exercise sessions), was required to proceed with the final statistical analyses. Therefore, after follow-up, the final sample size analyzed was as follows: CG $\left(n=13\right.$, age $40.0 \pm 11$ y, BMI $\left.28.3 \pm 3.6 \mathrm{~kg} / \mathrm{m}^{2}\right)$, HIIT $\left[n=14\right.$, age $37.0 \pm 9.0 \mathrm{y}$, BMI $28.6 \pm 3.6 \mathrm{~kg} / \mathrm{m}^{2}$, adherence mean 33 sessions (91\%)], RT [ $n=8$, age $34.0 \pm 9.0$ y, BMI $29.4 \pm 5.5 \mathrm{~kg} / \mathrm{m}^{2}$, adherence mean 20 sessions (83\%)], and CT [RT+HITT; $n=10$, age $43.0 \pm 8.0 \mathrm{y}$, BMI $29.1 \pm 3.0 \mathrm{~kg} / \mathrm{m}^{2}$, adherence mean 30 sessions (83\%)]. The study design is shown in Figure 1. The characteristics of the participants are shown in Table 1.

\section{Testing Procedures}

We measured FPG and fasting insulin (FI) to calculate HOMA-IR (Matthews et al., 1985). Blood samples $(\sim 3.5 \mathrm{ml})$ were taken between 8 and $10 \mathrm{~h}$ in the morning, after a 10-h overnight fast, in tubes with anticoagulant gels and placed on ice. Samples were then centrifuged at $4000 \mathrm{rpm}$. $(1700 \times g)$ for $5 \mathrm{~min}$ at $4^{\circ} \mathrm{C}$. Plasma samples were immediately transferred to pre-chilled microtubes and stored at $-20^{\circ} \mathrm{C}$ for later analysis. FPG was analyzed enzymatically, as described (Alvarez et al., 2016), using standard kits (Wiener Lab Inc., Rosario, Argentina) on an automatic analyzer (Metrolab 2,300 Plus ${ }^{\mathrm{TM}}$, Metrolab Biomed Inc., Buenos Aires, Argentina). FI was measured by radio-immune assay (DPC, Los Angeles, CA, United States), as described (Álvarez et al.,
2012). HOMA-IR was calculated using the equation: HOMA-IR $=[$ FPG $(\mathrm{mg} / \mathrm{dl}) \times$ FI $(\mu \mathrm{UI} / \mathrm{dl})] / 405$; Matthews et al., 1985). FPG, FI, and HOMA-IR were assessed at three different points: at baseline (pre), at $24-\mathrm{h}$, and at $72-\mathrm{h}$ after the last session of exercise or follow-up. We calculated the FPG, FI, and HOMA-IR delta changes from pre- to post-24h $\left(\Delta \mathrm{FPG}_{24 \mathrm{~h}}, \Delta \mathrm{FI}_{24 \mathrm{~h}}\right.$, and $\Delta$ HOMA-IR $\left.{ }_{24 \mathrm{~h}}\right)$ and from post- $24 \mathrm{~h}$ to post- $72 \mathrm{~h}\left(\Delta \mathrm{FPG}_{72 \mathrm{~h}}, \Delta \mathrm{FI}_{72 \mathrm{~h}}\right.$, and $\triangle$ HOMA-IR ${ }_{72 h}$ ) of the last exercise session. All laboratory analyses were carried out at the Riñihue Private Clinic (Los Lagos, Chile). The study protocol is shown in (Figure 2).

\section{Anthropometric and Body Composition Measurements}

Body mass was assessed by a digital weight scale with an accuracy of $0.1 \mathrm{~kg}$ (Omron HBF-INT ${ }^{\mathrm{TM}}$, Omron Healthcare Inc., Lake Forest, IL, United States). Height was assessed with a stadiometer (Health o Meter ${ }^{\mathrm{TM}}$ Professional, Sunbeam Products Inc., Chicago, IL, United States) with an accuracy of $0.1 \mathrm{~cm}$. Body mass index (BMI) was calculated according to the formula: $\mathrm{BMI}=$ body mass (in $\mathrm{kg}) /(\text { height })^{2}$ (in $\mathrm{m}$ ). Waist circumference (WC) was measured using a flexible and inextensible measuring tape (Hoechstmass ${ }^{\mathrm{TM}}$, Sulzbach, Germany) with precision to the nearest $0.1 \mathrm{~cm}$. Skinfold was measured using a Langue ${ }^{\mathrm{TM}}$ skinfold caliper (Beta Technology Inc., Santa Cruz, California, United States). Using the pre- vs. post- $24 \mathrm{~h}$, and post- $24 \mathrm{~h}$ vs. post-72 $\mathrm{h}$ time comparisons, we calculated the delta changes $(\Delta)$ as follows; delta waist circumference $(\Delta \mathrm{WC}$ in $\mathrm{cm})$, with delta tricípital $\left(\Delta \mathrm{T}_{\mathrm{SF}}\right)$, delta subscapular $\left(\Delta \mathrm{SE}_{\mathrm{SF}}\right)$, delta iliocristale $\left(\Delta \mathrm{IC}_{\mathrm{SF}}\right)$, and delta calf skinfold $\left(\Delta \mathrm{Calf}_{\mathrm{SF}}\right)$ in $\mathrm{mm}$. Skeletal muscle mass (SMM) was measured using a bioelectrical impedance analyzer (BIA) on a digital scale (Omron HBF-INTTM, Omron Health Inc., Lake Forest, IL, United States), with the participants asked not to wear metal, watches, or jewelry (Álvarez et al., 2019). The BIA contains a foot, heel, and grip electrode and requires the user to introduce information for age $(10-80 y)$, sex (male/female), and height $(100-199.5 \mathrm{~cm})$ of the participant. Thus, each participant in standing position holds the hand segment of the equipment for $30 \mathrm{~s}$ approximately at an angle of $90^{\circ}$ concerning the ground segment. Diameters of humeral (HumD), femoral (FemD), arm (ArmP), and calf (CalfP) perimeters were measured by using a small sliding bone caliper (Harpenden ${ }^{\mathrm{TM}}$, Canada) with $0.2 \mathrm{~mm}$ graduation and $0-80 \mathrm{~mm}$ range for measurement (Dykes et al., 1976). All outcomes were measured three times, with the average value registered. To the BIA analyses, all subjects were advised about to do not use metal jewelry, as well as to avoid abundant water $1 \mathrm{~h}$ before the measurement. All the skinfold measurements were carried out by the same evaluator at pre- and post-test.

\section{High-Intensity Interval Training Program}

HIIT was performed three times weekly (36 sessions) for 12-weeks, using a cycle ergometer (OXFORD ${ }^{\mathrm{TM}}$, model BE2601, Inc., Santiago, Chile). All participants received seven familiarization sessions before practicing HIIT. The participants performed a range of $8-12$ high-intensity cycling intervals of $60 \mathrm{~s}$, interspaced with $120 \mathrm{~s}$ of passive recovery 


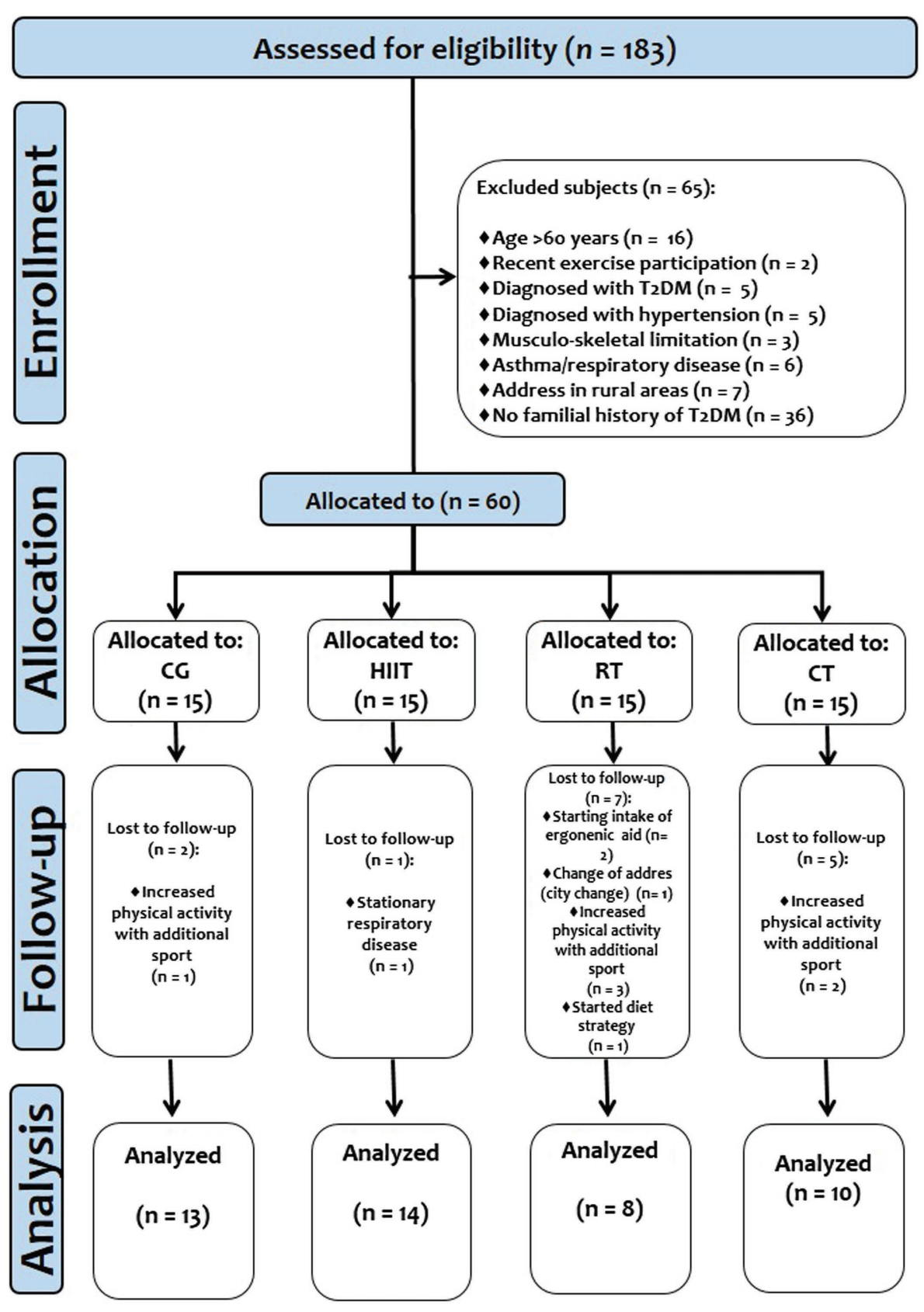

FIGURE 1 | Study design.

(seated on the bicycle and no moving). The rest period decreased progressively (120s in weeks $1-2,105 \mathrm{~s}$ in weeks $3-5,90 \mathrm{~s}$ in weeks $6-8$, and $75 \mathrm{~s}$ in weeks $9-10$, and $60 \mathrm{~s}$ in the final 12th week). Cycling revolutions at HIITs were maintained at 50 to $70 \mathrm{rpm}$., representing 20 to $40 \mathrm{~km} / \mathrm{h}$ of speed. Subjects were required to cycle between 8 and 10 points on the modified Borg scale during the work interval (Gillen et al., 2013). This intensity corresponded to $80-100 \%$ of the maximum heart rate according to a described formula (Karvonen and Vuorimaa, 1988).

\section{Resistance Training Program}

Using free weights with metal bars, participants developed four RT exercises, with a frequency of two times per week. However, they had a total of five exercise options and were required to swap between an upper body (first) and a lower body exercise, as follows: 1. biceps curl, 2. half squat, 3 . shoulder press, 4. calf raises, and 5. tricípital flexion/extension, plus two optional preventive exercises developed only by using their body weight (abdominal crunches and lower back concentric exercise). All participants received seven 
TABLE 1 | Baseline characteristics of the study cohort assigned to the exercise or control groups.

\begin{tabular}{|c|c|c|c|c|c|}
\hline \multirow{2}{*}{ Outcomes } & \multicolumn{4}{|c|}{ Groups } & \multirow{2}{*}{$\begin{array}{c}\text { Baseline } \\
F\left(\text {, value of } p \text {, effect size }\left(\eta^{2}\right)\right.\end{array}$} \\
\hline & $\mathbf{C G}^{\mathrm{a}}$ & $\mathrm{HIIT}^{\mathrm{b}}$ & $\mathbf{R} \mathbf{T}^{\mathbf{c}}$ & $\mathbf{C T}^{\mathrm{d}}$ & \\
\hline$(n)$ & 13 & 14 & 8 & 10 & \\
\hline Age (y) & $40.0 \pm 11.0$ & $37.0 \pm 9.0$ & $34.0 \pm 9.0$ & $43.0 \pm 8.0$ & $F_{(1.42)}, p=0.249,0.09$ \\
\hline Height (m) & $1.57 \pm 0.05$ & $1.55 \pm 0.04$ & $1.58 \pm 0.05$ & $1.55 \pm 0.04$ & $F_{(1.56)}, p=0.213,0.10$ \\
\hline \multicolumn{6}{|c|}{ Body composition/Anthropometric } \\
\hline $\begin{array}{l}\text { Body mass }(\mathrm{kg}) \\
\text { Body mass index }\left(\mathrm{kg} / \mathrm{m}^{2}\right) \\
\text { Skeletal muscle mass }(\%) \\
\text { Humeral diameter }(\mathrm{mm}) \\
\text { Femoral diameter }(\mathrm{mm}) \\
\text { Arm perimeter }(\mathrm{cm}) \\
\text { Calf perimeter }(\mathrm{cm})\end{array}$ & $\begin{aligned} 69.8 & \pm 10.5 \\
28.3 & \pm 3.6 \\
24.1 & \pm 2.7 \\
6.7 & \pm 0.9 \\
9.5 & \pm 1.3 \\
32.0 & \pm 2.0 \\
37.5 & \pm 4.2\end{aligned}$ & $\begin{array}{r}68.4 \pm 7.9 \\
28.6 \pm 3.6 \\
24.1 \pm 1.6 \\
6.2 \pm 0.4 \\
9.1 \pm 0.7 \\
33.0 \pm 3.0 \\
37.3 \pm 2.5\end{array}$ & $\begin{array}{r}74.6 \pm 17.9 \\
29.4 \pm 5.5 \\
24.2 \pm 1.9 \\
7.1 \pm 0.7 \\
9.3 \pm 1.0 \\
31.0 \pm 0.4 \\
36.7 \pm 2.2\end{array}$ & $\begin{array}{r}69.8 \pm 7.5 \\
29.1 \pm 3.0 \\
24.2 \pm 1.7 \\
6.6 \pm 0.8 \\
9.4 \pm 0.4 \\
33.0 \pm 2.0 \\
38.5 \pm 2.4\end{array}$ & $\begin{array}{l}F_{(0.19)}, p=0.889,0.02 \\
F_{(0.19)}, p=0.913,0.01 \\
F_{(0.02)}, p=0.994,0.003 \\
F_{(2.41)}, p=0.083,0.17 \\
F_{(0.57)}, p=0.639,0.64 \\
F_{(0.83)}, p=0.489,0.08 \\
F_{(0.27)}, p=0.845,0.03\end{array}$ \\
\hline \multicolumn{6}{|l|}{ Adiposity measures } \\
\hline $\begin{array}{l}\text { Waist circumference }(\mathrm{cm}) \\
\text { Tricipital skinfold }(\mathrm{mm}) \\
\text { Subscapular skinfold }(\mathrm{mm}) \\
\text { llio-cristale skinfold (mm) } \\
\text { Calf skinfold (mm) }\end{array}$ & $\begin{array}{l}95.7 \pm 9.2 \\
24.8 \pm 3.4 \\
30.2 \pm 2.6 \\
31.0 \pm 3.0 \\
19.8 \pm 10.8\end{array}$ & $\begin{array}{l}99.6 \pm 7.3 \\
24.5 \pm 2.6 \\
31.9 \pm 6.9 \\
32.4 \pm 4.3 \\
18.4 \pm 5.5\end{array}$ & $\begin{array}{r}100.6 \pm 15.5 \\
12.5 \pm 14.7 \\
26.1 \pm 11.7 \\
31.0 \pm 10.9 \\
23.0 \pm 11.4\end{array}$ & $\begin{array}{l}98.2 \pm 5.7 \\
20.9 \pm 6.3 \\
26.6 \pm 7.9 \\
24.7 \pm 5.7^{b} \\
20.2 \pm 7.4\end{array}$ & $\begin{array}{l}F_{(0.31)}, p=0.811,0.03 \\
F_{(1.16)}, p=0.341,0.11 \\
F_{(1.17)}, p=0.336,0.11 \\
F_{(0.45)}, \mathbf{p}=\mathbf{0 . 0 3 0}, 0.27 \\
F_{(0.34)}, p=0.791,0.03\end{array}$ \\
\hline
\end{tabular}

Data are shown as mean and $\pm S D$. Groups are described as: Control group (CG), High-intensity interval training (HIIT), Resistance training (RT), and Concurrent training (CT). Bold values denote significant pre-post changes at $p<0.05$ by repeated evaluations group $\times$ time. Univariant analysis was applied to test baseline differences among groups denoted by Sidak's post-hoc $\left(a, b, c\right.$, or d). values of $p$ for significant differences are shown in bold. $\eta^{2}$ denotes Lakens effect size.

familiarization sessions before the RT intervention. Progressive RT programs were performed three times per week for 12-weeks. The RT program consisted of an interval of work (performing voluntary extension/contraction) during $60 \mathrm{~s}$ in which a range of $8-10$ points of the modified Borg scale was reached in the final 55-60 s. The intensity in terms of $1 \mathrm{RM}$ corresponded to $20-40 \%$ at baseline and between 25 and $50 \%$ of the $1 \mathrm{RM}$ at the post-test. The recovery period was $120 \mathrm{~s}$ between sets. Each interval of work was repeated three times in the four exercises. The total intervals of work were 12 .

\section{Concurrent Training Program}

This program consisted of 3 weekly sessions and included RT first followed by HIIT exercises secondly, such as cycling sprints [for 40 (RT) and 20 (HIIT) minutes]. This choice was based on previous research experience for to be more efficient the exercise on health markers (Delgado-Floody et al., 2021). The number and types of RT exercises applied in the CT protocol included the same exercises as the RT program alone, which was performed with dumbbells, free weights, and metal bars, plus the two optional preventive exercises previously mentioned. Each RT exercise consisted of $60 \mathrm{~s}$ of concentric/eccentric voluntary movements, interspersed by $60 \mathrm{~s}$ of recovery. In the HIIT program, the participants performed a range of $8-12$ high-intensity cycling intervals of $60 \mathrm{~s}$, interspaced with $120 \mathrm{~s}$ of passive recovery (seated on the bicycle and no moving). The rest period decreased progressively ( $120 \mathrm{~s}$ in weeks $1-2,105 \mathrm{~s}$ in weeks $3-5,90 \mathrm{~s}$ in weeks $6-8,75 \mathrm{~s}$ in weeks $9-10$, and $60 \mathrm{~s}$ in the final $12^{\text {th }}$ week), in a similar protocol (i.e., volume and intensity) as was described in the HIIT program section. As additional information, and after intervention, the delta in percentage of $1 \mathrm{RM}$ changes $\left(\Delta_{\% 1 \mathrm{RM}}\right)$ was very similar between CT vs. RT by exercise; biceps curl $\Delta_{\% 1 \mathrm{RM}}+50.0 \%$ vs. $+25.0 \%$, half squat $\Delta_{\% 1 \mathrm{RM}}+18.7 \%$ vs. $+18.7 \%$, shoulder press $\Delta_{\% 1 \mathrm{RM}}+70.0 \%$ vs. $+70.0 \%$, gastrocnemius $\Delta_{\% 1 \mathrm{RM}}+210.0 \%$ vs. $+210.0 \%$, and triceps flexion/extension $\Delta_{\% 1 \mathrm{RM}}+28.0 \%$ vs. $+30.0 \%$ (data not shown).

For the HIIT and RT exercise sessions, subjects adhered to spend $45 \mathrm{kcal} \mathrm{kg}^{-1} \cdot \mathrm{min}^{-1}$ energy expenditure per session (HIIT; $12 \mathrm{~min}$, and RT; $12 \mathrm{~min}$, and cool-down/session 24 min), which was equivalent to $\sim 540 \mathrm{kcal}$ of expended energy per week; the CT sessions were based on $90 \mathrm{kcal} \cdot \mathrm{kg}^{-1} \cdot \mathrm{min}^{-1}$ energy expenditure per session ( $24 \mathrm{~min}$, and cool down/session $\sim 48 \mathrm{~min}$ ), which was equivalent to $\sim 1,080 \mathrm{kcal}$ of expended energy per week at the end of the training.

Each HIIT, RT, and CT program were performed in the morning from 9 to $12 \mathrm{~h}$.

\section{Residual Effects of HIIT, RT, and CT Post- 72-H of Training Cessation}

We applied the following two analyses: (a) pre- vs. post- $24 \mathrm{~h}$ (i.e., for training-induced changes) and (b) post- $24 \mathrm{~h}$ vs. post- $72 \mathrm{~h}$ for FPG and FI, and including the calculated HOMA-IR. We calculated the delta changes values $(\Delta)$ from the absolute values of FPG and FI. This resulted in (a) pre- vs. post- $24 \mathrm{~h}$ measurement for the outcomes $\Delta \mathrm{FPG}_{24 \mathrm{~h}}$, and $\Delta \mathrm{FI}_{24 \mathrm{~h}}$, and (b) post- $24 \mathrm{~h}$ vs. post- $72 \mathrm{~h}$ analyses, measuring the $\Delta \mathrm{FPG}_{72 \mathrm{~h}}$, and $\Delta \mathrm{FI}_{72 \mathrm{~h}}$ outcomes. The residual effect of the $\mathrm{CT}$ was extracted from the delta changes of the analyses of $\Delta \mathrm{FPG}_{72 \mathrm{~h}}$ and $\Delta \mathrm{FI}_{72 \mathrm{~h}}$ outcomes. All subjects were advised not to consume caffeine meals before and after the metabolic measurements.

After this procedure, we correlated the outcomes $\triangle F \mathrm{G}_{72} \mathrm{~h}$, $\Delta \mathrm{FI}_{72 \mathrm{~h}}$ with anthropometric and body composition outcomes generated from the 12-week interventions in each HIIT, RT, 


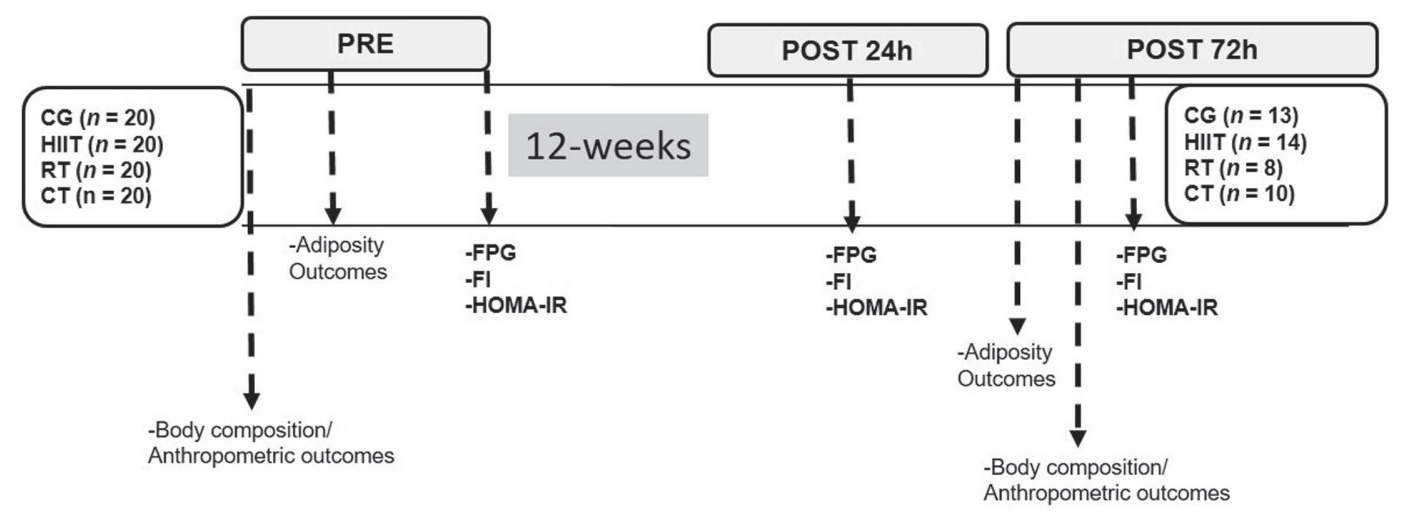

FIGURE 2 | Study protocol. Groups are described as control group (CG), high-intensity interval (HIIT), resistance training (RT), and concurrent training (CT). Outcomes are described as fasting plasma glucose (FPG), fasting insulin (FI), and homeostasis model assessment on insulin resistance (HOMA-IR).

and CT regimen including delta change of skeletal muscle mass $(\triangle \mathrm{SMM})$, humeral diameter $(\Delta \mathrm{HumD})$, femoral diameter $(\Delta \mathrm{FemD})$, arm perimeter $(\Delta \mathrm{ArmP})$, and calf perimeter $(\Delta \mathrm{CalfP})$.

Before starting the measurements of metabolic outcomes FPG, FI, and HOMA-IR at baseline, the basal metabolic rate information was delivered to each subject participant of the four groups (mean of basal metabolic rate baseline was of HIIT: $1307 \mathrm{kcal} /$ day, RT: $1403 \mathrm{kcal} /$ day, CT: $1291 \mathrm{kcal} /$ day, and CG: $1318 \mathrm{kcal} /$ day, according to with baseline age, height, weight, and sex). Thus, we recorded this information a post-test 24 and $72 \mathrm{~h}$ of the exercise cessation, in order to maintain these baseline patterns.

\section{Statistical Analysis}

Data are presented as the mean \pm standard deviation (in tables and figures). For the main outcomes, delta changes from pre- to post-24h were calculated for FPG, FI, and HOMA-IR $\left(\Delta \mathrm{FPG}_{24} \mathrm{~h}, \Delta \mathrm{FI}_{24} \mathrm{~h}\right.$, and HOMA-IR $\left.\mathrm{I}_{24 \mathrm{~h}}\right)$, and from post-24h to post-72h $\left(\Delta \mathrm{FPG}_{72 \mathrm{~h}}, \Delta \mathrm{FI}_{72 \mathrm{~h}}\right.$, and HOMA-IR $\left.\mathrm{R}_{72 \mathrm{~h}}\right)$. For secondary outcomes, delta changes were calculated only from pre- to post- $24 \mathrm{~h}$. The normality and homoscedasticity assumptions were tested by the Shapiro-Wilk test and Levene's test $(F)$, respectively. The Wilcoxon test was used for non-parametric data per group (Main outcomes; FI in HIIT, RT, and CT; HOMA-IR in HIIT and RT group, secondary outcomes; and Age in RT, SMM in CG, calf perimeter in CG, and humeral diameter in CT group). A repeated-measures ANOVA [groups $\times$ time (Pre-Post ${ }_{24 \mathrm{~h}}-$ Post $_{72 \mathrm{~h}}$ )] was used to assess traininginduced effects for the main metabolic outcomes (i.e., FPG, FI, and HOMA-IR) after 12-weeks of intervention, and all those outcomes measured at Pre-Post ${ }_{24 \mathrm{~h}}$. Subsequently, delta change values were calculated for the main and secondary outcomes, and Sidack's post-hoc test was applied when the $F$ value was significant. The Eta partial squared statistic for interaction (Time $\times$ Group) was assessed by $\eta^{2}$ obtained from the Univariant test with small $\left(\eta^{2}=0.01\right)$, medium $\left(\eta^{2}=0.06\right)$, and large $\left(\eta^{2}=0.14\right)$ effects defined according to Lakens (2013). An ANCOVA was conducted in adjustments for the baseline FPG values with age and BMI as covariates. After this, we applied a linear regression model to predict the $\triangle \mathrm{FPG}_{72 \mathrm{~h}}$ and $\Delta \mathrm{FI}_{72 \mathrm{~h}}$ changes using body composition, anthropometric, and adiposity outcomes, after using a multicollinearity test of tolerance and variance inflation. Statistical analyses were performed with SPSS statistical software version 18 (SPSSTM Inc., Chicago, Illinois, United States), and the graphs/figures were designed in GraphPad Prism version 8.0 version (USA) software. The alpha level was fixed at $p \leq 0.05$ for all statistical significance.

\section{RESULTS}

\section{Main Outcomes: Training-Induced Effects on FPG, Insulin, and HOMA-IR}

The overall baseline data and training-induced effects for the metabolic outcomes FPG, FI, and HOMA-IR are shown in Table 2 .

\section{Main Outcomes: Residual Effects on Metabolic Outcomes Post-24 H}

At training-induced changes, the HIIT intervention resulted in a marked decrease in FPG when comparing pre- vs. postcondition [mean $\pm \mathrm{SD}$, effect size $\left(\eta^{2}\right)$, value of $p$, in forward], FPG $101.0 \pm 2$ vs. $95.3 \pm 3.2 \mathrm{mg} / \mathrm{dl}, \eta^{2}: 0.07, p=0.021$; Figure 3A). FI significantly decreased after the RT intervention from preto post-test $\left(4.9 \pm 1.6\right.$ vs. $4.3 \pm 1.5 \mu \mathrm{UI} / \mathrm{L}, \eta^{2}: 0.48, p=0.035$; Figure 3B), and no significant changes were observed for HOMA-IR (Figure 3C).

At residual effects, in FPG, at the $24 \mathrm{~h}$, they were significant time $\times$ group interaction among groups $\left[F_{(3.16)}, \eta^{2}: 0.20\right.$, $p=0.035]$, with significant differences in the delta $(\Delta)$ effects between HIIT $\Delta \mathrm{FPG}_{24 \mathrm{~h}}-5.9$ vs. $\mathrm{CG}+0.9 \mathrm{mg} / \mathrm{dl}, \eta^{2}: 0.19$, $p<0.0001$, and between RT $\Delta \mathrm{FPG}_{24 \mathrm{~h}}-5.5 \mathrm{vs}$. CG $+0.9 \mathrm{mg} /$ $\mathrm{dl}, \eta^{2}: 0.26, p<0.0001$, but no differences were found between HIIT, RT, and CT (Figure 3D). At $24 \mathrm{~h}$, no time $\times$ group interactions were found for FI (Figure 3E) and HOMA-IR (Figure 3F). 
TABLE 2 | Changes in plasma markers of insulin-resistant adult women, participants of 12-weeks of high-intensity interval, resistance, concurrent training, or a control group.

\begin{tabular}{|c|c|c|c|c|c|}
\hline Outcomes & Time & $\mathbf{C G}^{\mathrm{a}}$ & HIIT $^{\mathrm{b}}$ & $\mathbf{R} \mathbf{T}^{\mathbf{c}}$ & $\mathbf{C T}^{\mathrm{d}}$ \\
\hline$(n=)$ & & 13 & 14 & 8 & 10 \\
\hline \multirow[t]{3}{*}{ Fasting plasma glucose (mg/dl) } & Pre & $102.0 \pm 9.0$ & $101.0 \pm 0.9$ & $98.0 \pm 13.0$ & $99.0 \pm 5.0$ \\
\hline & Post $_{24 h}$ & $103.1 \pm 9.4$ & $95.3 \pm 12.1^{* * *}$ & $92.9 \pm 9.6$ & $96.7 \pm 4.4$ \\
\hline & Post $_{72 \mathrm{~h}}$ & $103.4 \pm 8.8$ & $96.5 \pm 12.8$ & $93.9 \pm 5.6$ & $103.3 \pm 6.1^{* * * *}$ \\
\hline \multirow[t]{3}{*}{ Fasting insulin ( $\mu \mathrm{Ul} / \mathrm{dl})$} & Pre & $3.6 \pm 1.7$ & $4.6 \pm 2.9$ & $4.9 \pm 4.6$ & $4.5 \pm 4.8$ \\
\hline & Post $_{24 h}$ & $3.7 \pm 1.7$ & $4.9 \pm 5.0$ & $4.3 \pm 4.1$ & $4.7 \pm 4.3$ \\
\hline & Post $_{72 \mathrm{~h}}$ & $3.8 \pm 1.7$ & $4.4 \pm 2.8$ & $2.8 \pm 2.0$ & $4.5 \pm 4.2$ \\
\hline \multirow[t]{3}{*}{ HOMA-IR } & Pre & $0.9 \pm 0.5$ & $1.2 \pm 0.8$ & $1.3 \pm 1.5$ & $1.1 \pm 1.1$ \\
\hline & Post $_{24 h}$ & $1.0 \pm 0.5$ & $1.2 \pm 1.2$ & $1.1 \pm 1.2$ & $1.1 \pm 1.1$ \\
\hline & Post $_{72 \mathrm{~h}}$ & $1.0 \pm 0.5$ & $1.1 \pm 0.7$ & $0.6 \pm 0.2$ & $1.2 \pm 1.2$ \\
\hline
\end{tabular}

${ }^{* *}$ Significant differences from pre- to post-24h by two-way ANOVA (group $\times$ times) at $p<0.001$.

${ }^{* * *}$ Significant differences from post-24h to post-72 $h$ by two-way ANOVA (Group $\times$ Time) at $p<0.001$.

Data are shown as mean and $\pm S D$. Groups are described as: Control group (CG), High-intensity interval (HIIT), Resistance training (RT), and Concurrent training (CT). Bold values denote significant pre-post changes at $p<0.05$ by repeated evaluations $\times$ group. Univariant analysis was applied to test baseline differences among groups denoted ( $a, b, c$, or $d)$. value of $p$ significant differences was remarked in bold.

\section{Main Outcomes: Residual Effects on Metabolic Outcomes Post-72 H}

In FPG, at the $72 \mathrm{~h}$, they were significant time $\times$ group interaction among groups $\left[F_{(6.25)}, \eta^{2}: 0.33, p=0.001\right]$, with significant differences in the delta $(\Delta)$ effects between $\mathrm{CT} \Delta \mathrm{FPG}_{72 \mathrm{~h}}+6.6 \mathrm{vs}$. CG $+0.3 \mathrm{mg} /$ $\mathrm{dl}, \eta^{2}: 0.76, p<0.0001$, between CT $\Delta \mathrm{FPG}_{72 \mathrm{~h}}+6.6$ vs. HIIT $+1.2 \mathrm{mg} /$ $\mathrm{dl}, \eta^{2}: 0.07, p=0.004$, and between $\mathrm{CT} \Delta \mathrm{FPG}_{72 \mathrm{~h}}+6.6$ vs. RT $1.0 \mathrm{mg} / \mathrm{dl}, \eta^{2}: 0.05, p=0.010$ (Figure 3G), but no interactions were found for FI (Figure 3H) and HOMA-IR (Figure 3I).

\section{Secondary Outcomes: Body Composition and Anthropometric Markers Post- 12-Weeks}

In SMM, they were significant time $\times$ group interaction among groups $\left[F_{(5.81)}, \eta^{2}: 0.31, p=0.002\right]$, with significant differences in the delta $(\Delta)$ effects between CT $\Delta \mathrm{SMM}+0.6$ vs. $\mathrm{CG}+0.2 \mathrm{~kg}, \eta^{2}$ : $0.48, p=0.014$ and between CT $\Delta \mathrm{SMM}+0.6$ vs. HIT $-0.1 \mathrm{~kg}$, $\eta^{2}: 0.03, p=0.050$ (Figure 4A). In the $\Delta \mathrm{HumD}$, there were significant time $\times$ group interaction among groups $\left[F_{(3.35)}, \eta^{2}: 0.22, p=0.030\right]$, with significant differences in the delta $(\Delta)$ effects between RT $\Delta \mathrm{HumD}+0.05$ vs. CT $+0.01 \mathrm{~mm}, \eta^{2}: 0.000, p=0.050$ (Figure 4 B). No time $\times$ group interaction was observed in FemD (Figure 4C). In $\triangle \mathrm{ArmP}$, and despite that they were observed significant time $\times$ group interaction among groups $\left[F_{(8.35)}, \eta^{2}: 0.51, p=0.001\right]$, no significant differences among the delta $(\Delta)$ effects were found between CT vs. HIIT, RT, or CG, (Figure $4 \mathrm{D}$ ). No time × group interaction was observed in CalfP (Figure 4E).

\section{Secondary Outcomes: Adiposity Markers Post-12-Weeks}

In WC, they were significant time $\times$ group interaction among groups $\left[F_{(17.8)}, \eta^{2}: 0.58, p<0.0001\right]$, with significant differences in the delta $(\Delta)$ effects between CT $\Delta \mathrm{WC}-3.6$ vs. $\mathrm{CG}+0.9 \mathrm{~cm}, \eta^{2}$ : $0.44, p<0.0001$, (Figure 5A). In $\mathrm{T}_{\mathrm{SF}}$, despite they were significant time $\times$ group interaction among groups $\left[F_{(4.60)}, \eta^{2}: 0.36, p=0.011\right]$, no differences were found among the delta $(\Delta)$ effects between CT vs. HIIT, RT, or CG (Figure 5B). In $\mathrm{SE}_{\mathrm{SF}}$ there were significant time $\times$ group interaction among groups $\left[F_{(10.0)}, \eta^{2}: 0.55, p<0.0001\right]$, with significant differences in $(\Delta)$ effects between $\mathrm{CT} \Delta \mathrm{SE}_{\mathrm{SF}}-1.7$ vs. $\mathrm{CG}+0.6 \mathrm{~mm}, \eta^{2}: 0.62, p=0.016$ (Figure $5 \mathrm{C}$ ). In $\mathrm{IC}_{\mathrm{SF}}$, there were significant time $\times$ group interaction among groups $\left[F_{(10.6)}\right.$, $\left.\eta^{2}: 0.16, p<0.0001\right]$, with significant differences in $(\Delta)$ effects between $\mathrm{CT} \Delta \mathrm{IC}_{\mathrm{SF}}-2.5$ vs. $\mathrm{CG}+1.0 \mathrm{~mm}, \eta^{2}: 0.72, p=0.005$

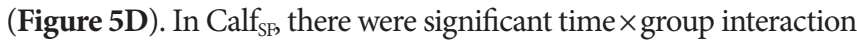
among groups $\left[F_{(9.82)}, \eta^{2}: 0.16, p<0.0001\right]$, with significant differences in $(\Delta)$ effects between CT $\Delta$ Calf $_{\mathrm{SF}}-3.0$ vs. CG $+0.1 \mathrm{~mm}, \eta^{2}: 0.48$, $p<0.0001$, between CT $\Delta$ Calf $_{\mathrm{SF}}-3.0$ vs. HIIT $-1.1 \mathrm{~mm}, \eta^{2}: 0.97$, $p=0.016$, and between CT $\Delta$ Calf $_{\mathrm{SF}}-3.0$ vs. RT $-0.9 \mathrm{~mm}, \eta^{2}$ : $0.84, p=0.009$ (Figure 5E).

\section{Training-Induced Changes From CT for Predicting Residual Effects on FPG and Insulin Changes Post-72 H}

Using a linear regression model and considering the delta changes in $\triangle \mathrm{FPG}_{72 \mathrm{~h}}$, 4 out of 5 adaptations, such as body composition/ anthropometry [model 1 (30.8\%) $\Delta \mathrm{SMM}, r=-0.55, p<0.001$ ]; model $2(51.0 \%) \Delta \mathrm{SMM}+\Delta \mathrm{HumD}, r=-0.50, p=0.002$; model $3(57.6 \%) \quad \Delta \mathrm{SMM}+\Delta \mathrm{HumD}+\Delta \mathrm{FemD}, r=0.21, p=0.004$; and model $4(62 \%) \quad \Delta \mathrm{SMM}+\Delta \mathrm{HumD}+\Delta \mathrm{FemD}+\Delta \mathrm{ArmP}, r=0.62$, $p=0.015$; Table 3), as well as adiposity adaptations [model 1 (17.5\%) $\Delta \mathrm{WC}, r=0.41, p=0.009]$; model $2(28.3 \%) \Delta \mathrm{WC}+\Delta \mathrm{T}_{\mathrm{SF}}$ $r=-0.22, p=0.014$; and [model $3(28.7 \%) \Delta \mathrm{WC}+\Delta \mathrm{T}_{\mathrm{SF}}+\Delta \mathrm{SE}_{\mathrm{SF}}$ $r=0.05, p=0.037$ ], predicted in different percentages (i.e., from 17.5 to $62.6 \%$ ) the $\mathrm{FPG}_{72 \mathrm{~h}}$ in the CT group (Table 3).

On the other hand, the body composition/anthropometry was the unique model for predicting changes in $\Delta \mathrm{FI}_{72 \mathrm{~h}}$ after CT exercise intervention, by model $5 \quad[(99.7 \%) \quad \Delta \mathrm{SMM}+\Delta \mathrm{HumD}+$ $\Delta \mathrm{FemD}+\Delta \mathrm{ArmP}+\Delta \mathrm{CalfP}, r=0.01, p=0.036]$ (Table 4).

\section{DISCUSSION}

The present study aimed to assess the residual effects (post72-h training cessation) on FPG and FI after 12-weeks of HIIT, RT, or CT in women with IR. We also aimed to determine the training-induced, post-training residual impact of CT. The 
A

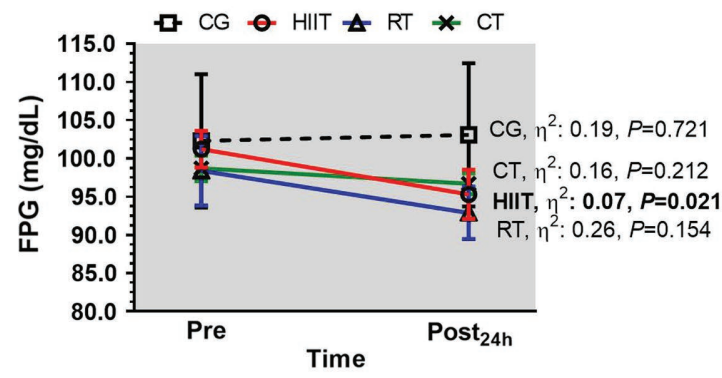

B

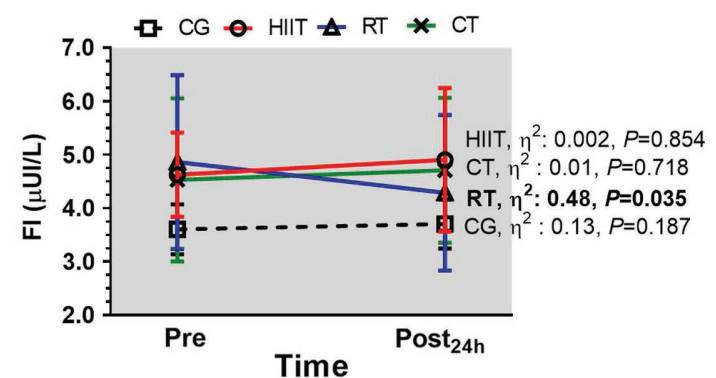

C

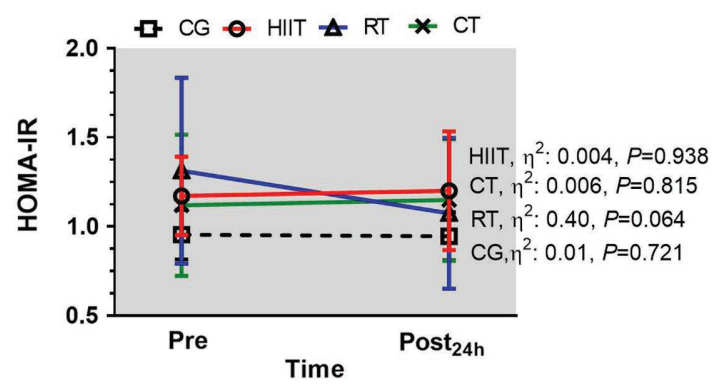

Delta Pre-Post24h

Time $x$ Group interaction $F_{(3.16)}, p=0.035, \eta^{2}=0.20$

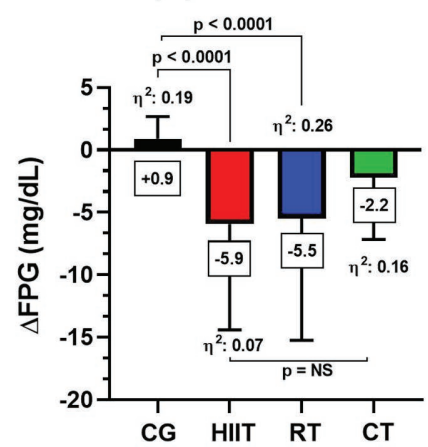

E

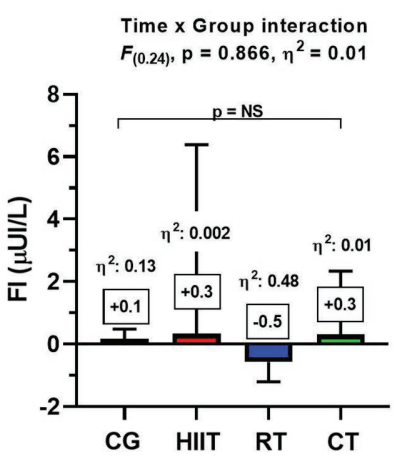

F

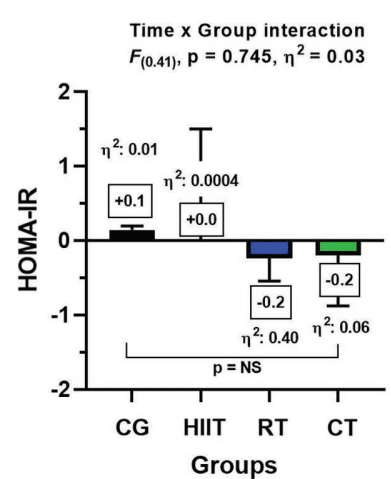

G

\section{Delta Post24h-Post72h}

Time $x$ Group interaction $F_{(6.25)}, p=0.001, \eta^{2}=0.33$

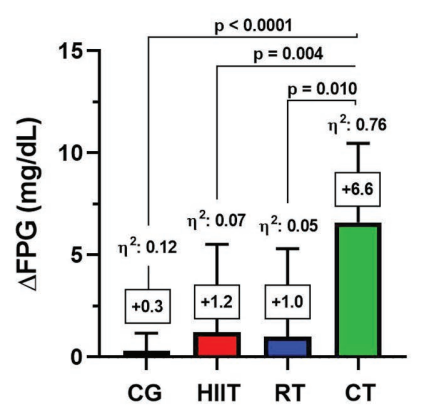

H
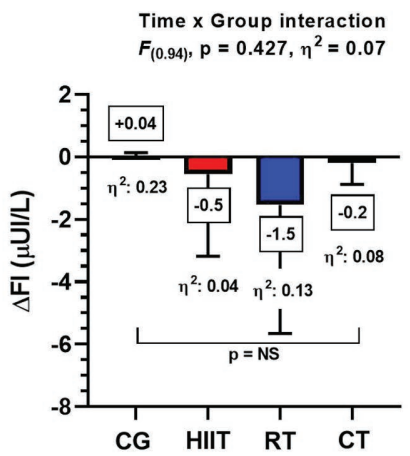

I

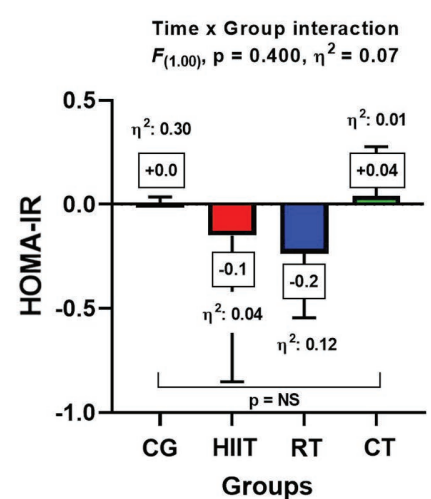

FIGURE 3 | Long-term (A-C) and acute post-24h (D-F) and post-72h changes (G-I) in metabolic outcomes in adult women with insulin resistance after 12-weeks of the three different exercise trainings or a control group. Panels (A-C) show values in mean \pm SEM during the exercise period. Panels (D-F) show values in "delta changes" (from pre- to post-24h). Panels (G-I) show values in "delta $(\Delta)$ changes" (from post-24h to post-72h). Groups are described as: control group (CG), highintensity interval training (HIIT), resistance training (RT), and concurrent training (CT). Outcomes are described as: fasting plasma glucose (FPG), fasting insulin (FI), and homeostasis model assessment of insulin resistance (HOMA-IR). $\Delta \mathrm{FPG}_{24 \mathrm{~h}}, \Delta \mathrm{Fl}_{24 \mathrm{~h}}$, and $\Delta \mathrm{HOMA}-\mathrm{IR}_{24 \mathrm{~h}}$ in panels (D-F), respectively, denote deltas from pre- to post-test $24 \mathrm{~h}$ after the last exercise session. $\Delta \mathrm{FPG} \mathrm{G}_{72 \mathrm{~h}}, \Delta \mathrm{FI}_{72 \mathrm{~h}}$, and $\Delta \mathrm{HOMA}-\mathrm{IR}_{72 \mathrm{~h}}$ in panels $(\mathbf{G}-\mathbf{I})$, respectively, denote deltas from post-24h to post-72h after the last exercise session. Within-group changes are described with specific at values of $p \leq 0.05$ in bold in (A,D,G). Between-group changes are described in bold values in panels (D-I).

main findings were as follows: (i) HIIT decreases FPG and RT decreases FI 24-h post-training, (ii) both HIIT and RT exercises alone show improved residual effects on FPG and FI (post-72h) compared with the CT intervention where at this time their effects are worsened, and (iii) adiposity-related markers [model 2: $\left.\Delta \mathrm{WC}+\Delta \mathrm{T}_{\mathrm{SF}}, R^{2} 0.62(62 \%)\right]$ together with body composition/anthropometric adaptations [model 4: $\left.\Delta \mathrm{SMM}+\Delta \mathrm{HumD}+\Delta \mathrm{FemD}+\Delta \mathrm{ArmP}, R^{2} 0.28(28 \%)\right]$ models mostly explain the poorer residual effects promoted by the CT intervention. These results highlight that both adiposity reduction particularly, together with SMM, and bone increases play a particular role in the residual effects after CT. 


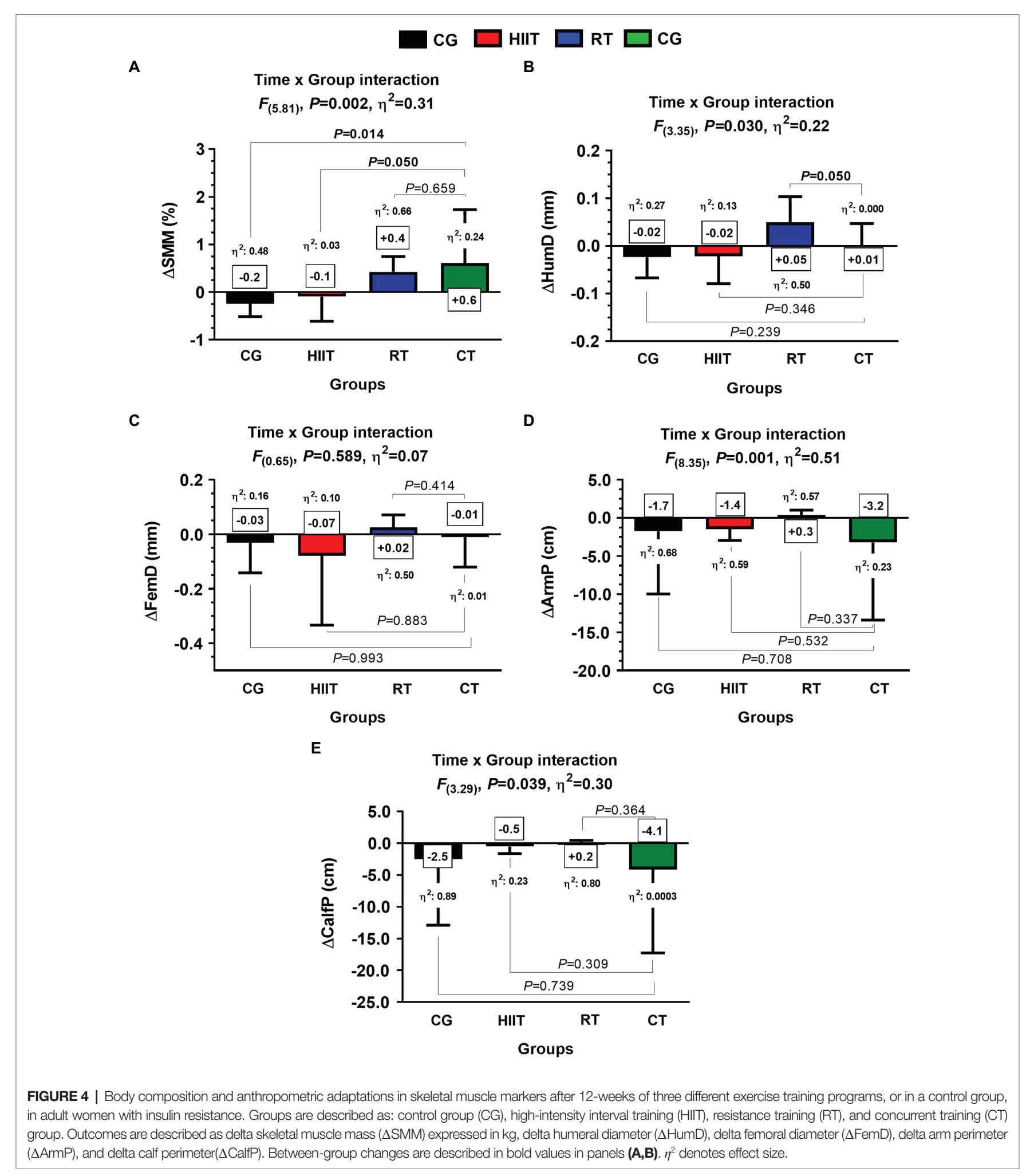

While there is a large body of evidence on the traininginduced changes in metabolic markers after HIIT (Little et al., 2011; Jelleyman et al., 2015; Alvarez et al., 2016; Matos et al., 2018), RT (Dunstan et al., 2002; Wood and O'Neill, 2012), and CT (Timmons et al., 2018; Álvarez et al., 2019), evidence is sparse concerning their residual effects post-exercise, particularly for CT. For instance, Marcus et al. (2013) showed that despite 16-weeks of RT in patients with T2DM, which promoted an improvement in SMM $(\Delta 8 \%)$ and regional insulin sensitivity based on a euglycemic-hyperinsulinemic clamp 
CG

A

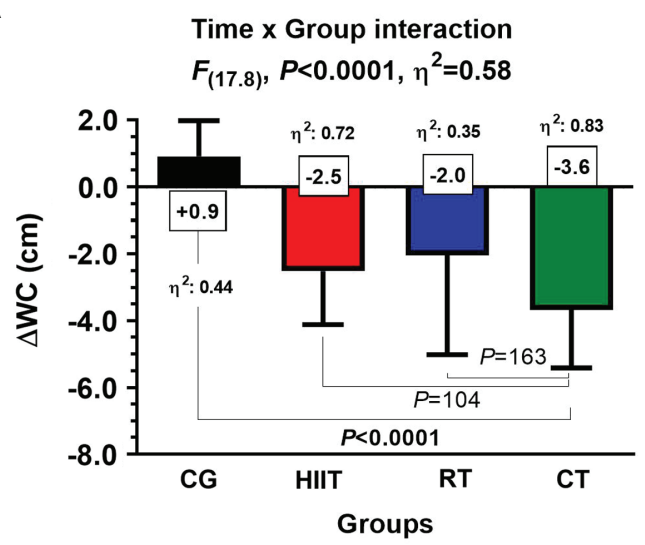

C

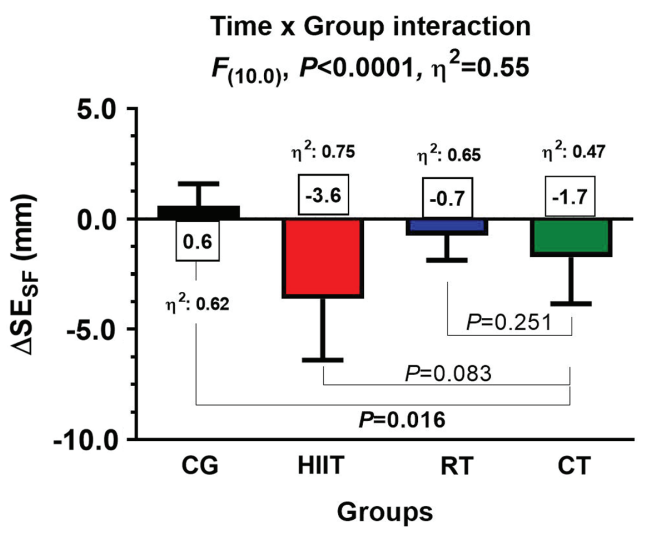

B

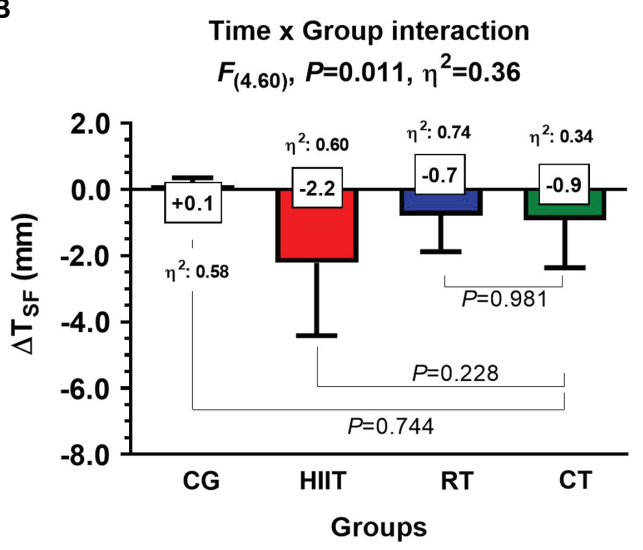

D

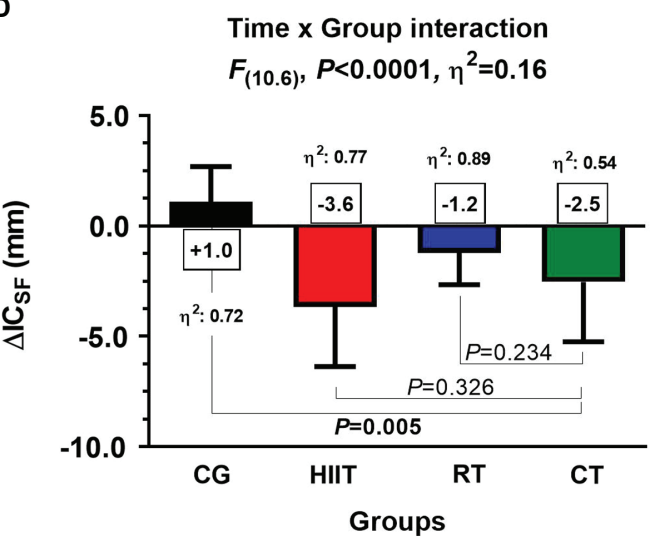

E

Time $x$ Group interaction

$F_{(9.82)}, P<0.0001, \eta^{2}=0.16$

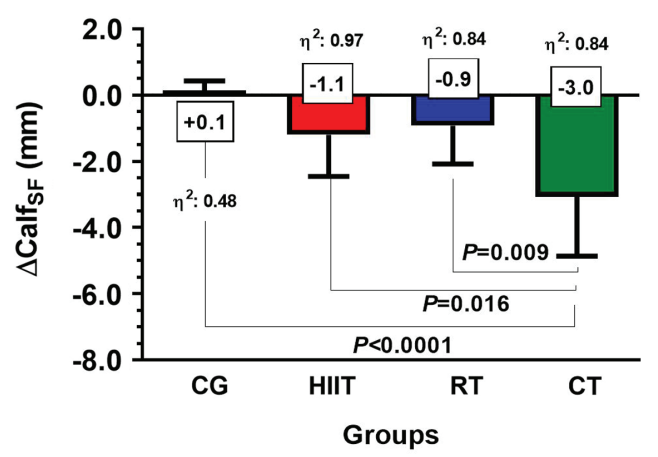

FIGURE 5 | Adaptations of adiposity markers after 12-weeks of three different exercise training programs, or in a control group, in adult women with insulin resistance. Groups are described as: control group (CG), high-intensity interval training (HIIT), resistance training (RT), and concurrent training (CT). Outcomes are described as delta waist circumference $(\Delta \mathrm{WC})$, delta tricípital skinfold $\left(\Delta \mathrm{T}_{\mathrm{SF}}\right)$, delta subscapular skinfold $\left(\Delta \mathrm{SE} \mathrm{E}_{\mathrm{SF}}\right)$, delta ilio-cristale skinfold $\left(\Delta \mathrm{I} \mathrm{C}_{\mathrm{SF}}\right)$, and delta calf skinfold $\left(\Delta\right.$ Calf $\left._{\mathrm{SF}}\right)$. Panel A show waist circumference, panel B tricícital skinfold, panel $\mathbf{C}$ subescapular skinfold, panel $\mathbf{D}$ ilio-crestale skinfold, and panel E calf skinfold. Betweengroup differences are described in bold values from panels (A-E). $\eta^{2}$ denotes effect size.

$(\Delta 33.9 \%)$, there was a loss in whole-body insulin sensitivity $(\Delta-12.4 \%) 7$ days after exercise csessation even though SMM was maintained. Also, when highly trained athletes and young people were participating under MICT, these showed showed an increase in FI and a decrease in insulin sensitivity after 5 to 7 days post-training (Vukovich et al., 1996; Goulet et al., 2005). Contrastingly, the present study shows that after 12 -weeks of HIIT, RT, or CT, only HIIT and RT groups showed improve $\triangle \mathrm{FPG}_{24} \mathrm{~h}$, and the RT group showed improved $\Delta \mathrm{FI}_{24 \mathrm{~h}}$. Nevertheless, our data reveal that improvements from HIIT 
TABLE 3 | Body composition/anthropometric and adiposity outcomes (delta changes) predicting the changes in fasting plasma glucose from post- $24 \mathrm{~h}$ to post-72 $\mathrm{h}$ in participants after 12-weeks of concurrent training.

\begin{tabular}{|c|c|c|c|c|}
\hline $\begin{array}{l}\text { Models for } \\
\text { predicting } \\
\triangle \mathrm{FPG}_{72 \mathrm{~h}}\end{array}$ & $\begin{array}{c}R^{2} \\
\text { (\% of } \\
\text { Prediction) }\end{array}$ & $\beta(95 \% \mathrm{Cl})$ & $r=$ & $\begin{array}{c}\text { Model } \\
\text { value of } \\
p\end{array}$ \\
\hline \multicolumn{5}{|c|}{ Body composition/anthropometry outcomes } \\
\hline $\begin{array}{l}\text { Model } 1 \\
\text { Model } 2 \\
\text { Model } 3 \\
\text { Model } 4 \\
\text { Model } 5\end{array}$ & $\begin{array}{l}0.308(\mathbf{3 0 . 8} \%)^{\dagger} \\
0.510(\mathbf{5 1 . 0 \%})^{\dagger} \\
0.576(\mathbf{5 7 . 6 \%})^{\dagger} \\
0.626(\mathbf{6 2 . 6 \%})^{\dagger} \\
0.640(64.0 \%)\end{array}$ & $\begin{array}{l}-0.55(-4.4,0.8) \\
-0.46(-4.1,1.1) \\
-0.55(-4.9,1.3) \\
-0.38(-6.0,3.5) \\
-0.53(-12.5,9.1)\end{array}$ & $\begin{array}{r}-0.55 \\
-0.50 \\
0.21 \\
0.62 \\
0.24\end{array}$ & $\begin{array}{l}p<0.001 \\
p=0.002 \\
p=0.004 \\
p=0.015 \\
p=0.069\end{array}$ \\
\hline \multicolumn{5}{|c|}{ Adiposity outcomes } \\
\hline $\begin{array}{l}\text { Model } 1 \\
\text { Model } 2 \\
\text { Model } 3 \\
\text { Model } 4 \\
\text { Model } 5\end{array}$ & $\begin{array}{l}0.175(\mathbf{1 7 . 5} \%)^{\dagger} \\
0.283(\mathbf{2 8 . 3} \%)^{\dagger} \\
0.287(\mathbf{2 8 . 7} \%)^{\dagger} \\
0.312(31.2 \%) \\
0.468(46.8 \%)\end{array}$ & $\begin{array}{l}0.41(-0.80,2.51) \\
0.49(-0.76,2.79) \\
0.50(-1.02,3.08) \\
0.46(-1.55,3.45) \\
0.32(-2.39,3.73)\end{array}$ & $\begin{array}{r}0.41 \\
-0.22 \\
0.05 \\
0.23 \\
0.23\end{array}$ & $\begin{array}{l}\mathbf{p}=\mathbf{0 . 0 0 9} \\
\mathbf{p}=\mathbf{0 . 0 1 4} \\
\mathbf{p}=\mathbf{0 . 0 3 7} \\
p=0.061 \\
p=0.089\end{array}$ \\
\hline
\end{tabular}

${ }^{t}$ denotes models that predict significantly the changes in FPG post-72h of training cessation.

Delta fasting plasma glucose $\left(\triangle F P G_{72 h}\right)$ from post-24h to post-72h. Outcomes are described as: delta skeletal muscle mass ( $\triangle S M M)$ expressed in percentage, delta humeral diameter $(\Delta$ HumD), delta femoral diameter $(\Delta$ FemD), delta arm perimeter $(\triangle A r m P)$, and delta calf perimeter $(\Delta C$ CalfP). delta waist circumference $(\Delta W C)$, delta tricípital skinfold $\left(\Delta T_{S F}\right)$, delta subscapular skinfold $\left(\Delta S E_{S F}\right)$, supra-iliac skinfold $\left(\Delta S I_{S F}\right)$, and delta calf skinfold

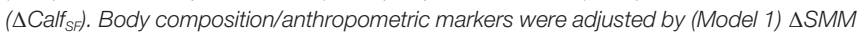
non-adjusted model, (Model 2) $\triangle S M M$ adjusted by $\triangle$ HumD, (Model 3) $\triangle S M M$ adjusted by $\triangle$ HumD and $\triangle$ FemD, (Model 4) $\triangle S M M$ adjusted by $\triangle$ HumD, $\triangle$ FemD, and $\triangle A r m P$, and (Model 5) $\triangle S M M$ adjusted by $\triangle$ HumD, $\triangle F e m D, \triangle$ ArmP, and $\triangle$ CalfP. Adiposity markers were adjusted by (Model 1) $\Delta W C$ non-adjusted model, (Model 2) $\Delta W C$ adjusted by $\Delta T_{S F}$ (Model 3) $\Delta W C$ adjusted by $\Delta T_{S F}$ and $\Delta S E_{S F}$ (Model 4) $\Delta W C$ adjusted by $\Delta T_{S F} \Delta S E_{S F}$ and $\Delta / C_{S F}$ and (Model 5) $\Delta W C$ adjusted by $\Delta T_{S F} \Delta S E_{S F} \Delta / C_{S F}$ and $\Delta$ Calf $f_{S F}$ Bold values denote significant association at $p<0.05$ by different linear regression models; Pearson r-test ( $r$ ).

in $\triangle \mathrm{FPG}_{24 \mathrm{~h}}$ were then worsened after $72 \mathrm{~h}$ of exercise cessation $\left(\Delta \mathrm{FPG}_{72 \mathrm{~h}}+1.2 \mathrm{mg} / \mathrm{dl}\right)$, from RT these worsened was from -5.5 at $24 \mathrm{~h}$ to +1.0 at $72 \mathrm{~h}$, but more worryingly in CT from -2.0 at $24 \mathrm{~h}$ to $+6.6 \mathrm{mg} / \mathrm{dl}$ at post $-72 \mathrm{~h}$, which is similar to previous reports (Vukovich et al., 1996; Goulet et al., 2005). Accordingly, our data along with the aforementioned evidence suggest that HIIT, and RT alone, but also CT can decrease (i.e., significant or not) FPG particularly 24-h post-exercise cessation, but however is the CT regime that shows a minor efficiency for maintaining these beneficial residual effect post- $72 \mathrm{~h}$ of exercise cessation. These results open the door for speculating that the positive metabolic adaptations promoted during exercise training participation could be critically dependent on maintaining this regular exercise routine in this precise metabolic topic of IR patients, but it is a matter of future and more complex studies to corroborate these findings.

Regarding the physiological mechanisms related to anthropometric/body composition on metabolic control, it is well known that SMM plays an important role in glucose control through peripheral glucose uptake (Richter et al., 1988). In the present study, we observed minimal increases in SMM in the RT $(\Delta \mathrm{SMM} ;+0.4 \%)$ and CT $(\Delta \mathrm{SMM} ;+0.6 \%)$ groups (Table 1 and Figure 4A). Additionally, other outcomes could be involved in the beneficial residual effects on glucose control post-exercise,
TABLE 4 | Body composition/anthropometric and adiposity outcomes (delta changes) predicting the changes in FI from post- $24 \mathrm{~h}$ to post- $72 \mathrm{~h}$ in participants after 12-weeks of concurrent training.

\begin{tabular}{|c|c|c|c|c|}
\hline $\begin{array}{l}\text { Models for } \\
\text { predicting } \\
\Delta \mathrm{FI}_{72 \mathrm{~h}}\end{array}$ & $\begin{array}{c}R^{2} \\
\text { (\% of } \\
\text { Prediction) }\end{array}$ & $\beta(95 \% \mathrm{Cl})$ & $r=$ & $\begin{array}{c}\text { Model } \\
\text { value of } p\end{array}$ \\
\hline \multicolumn{5}{|c|}{ Body composition/anthropometry outcomes } \\
\hline $\begin{array}{l}\text { Model } 1 \\
\text { Model } 2 \\
\text { Model } 3 \\
\text { Model } 4 \\
\text { Model } 5\end{array}$ & $\begin{array}{l}0.018(1.8 \%) \\
0.776(77.6 \%) \\
0.815(81.5 \%) \\
0.988(98.8 \%) \\
0.997(\mathbf{9 9 . 7 \%})^{\dagger}\end{array}$ & $\begin{array}{r}-0.13(-0.64,0.51) \\
0.04(-0.30,0.35) \\
0.11(-0.32,0.45) \\
0.21(-0.29,0.03) \\
-0.08(-0.23,0.13)\end{array}$ & $\begin{array}{r}-0.13 \\
0.88 \\
0.03 \\
0.54 \\
0.01\end{array}$ & $\begin{array}{l}p=0.799 \\
p=0.379 \\
p=0.287 \\
p=0.071 \\
\mathbf{p}=\mathbf{0 . 0 3 6}\end{array}$ \\
\hline \multicolumn{5}{|c|}{ Adiposity outcomes } \\
\hline $\begin{array}{l}\text { Model } 1 \\
\text { Model } 2 \\
\text { Model } 3 \\
\text { Model } 4 \\
\text { Model } 5\end{array}$ & $\begin{array}{l}0.079(7.9 \%) \\
0.137(13.7 \%) \\
0.196(19.6 \%) \\
0.266(26.6 \%) \\
0.286(28.6 \%)\end{array}$ & $\begin{array}{l}-0.28(-0.44,0.22) \\
-0.33(-0.50,0.24) \\
-0.36(-0.56,0.27) \\
-0.29(-0.61,0.37) \\
-0.34(-0.81,0.54)\end{array}$ & $\begin{array}{r}-0.28 \\
0.17 \\
0.14 \\
-0.19 \\
0.19\end{array}$ & $\begin{array}{l}p=0.316 \\
p=0.369 \\
p=0.573 \\
p=0.583 \\
p=0.870\end{array}$ \\
\hline
\end{tabular}

${ }^{t}$ denotes models that predict significantly the changes in Fl post-72 $\mathrm{h}$ of training cessation.

Delta fasting insulin $\left(\Delta \mathrm{FI}_{72 h}\right)$ from post-24h to post-72 $\mathrm{h}$. Outcomes are described as: delta skeletal muscle mass ( $\triangle S M M)$ expressed in percentage, delta humeral diameter ( $\triangle H$ HumD), delta femoral diameter $(\triangle F e m D)$, delta arm perimeter $(\triangle A r m P)$, and delta calf perimeter ( $\Delta$ CalfP). delta waist circumference $(\Delta W C)$, delta tricipital skinfold $\left(\Delta T_{S F}\right)$, delta subscapular skinfold $\left(\Delta S E_{S F}\right)$, supra-iliac skinfold $\left(\Delta S I_{S F}\right)$, and delta calf skinfold $\left(\Delta C a l f_{S F}\right)$. Body composition/anthropometric markers were adjusted by (Model 1) $\triangle S M M$ non-adjusted model, (Model 2) $\triangle S M M$ adjusted by $\triangle H u m D$, (Model 3) $\triangle S M M$ adjusted by $\triangle H$ HumD and $\triangle$ FemD, (Model 4) $\triangle S M M$ adjusted by $\triangle H$ HumD, $\triangle$ FemD, and $\triangle$ ArmP, and (Model 5) $\triangle S M M$ adjusted by $\Delta$ HumD, $\triangle F e m D, \triangle A r m P$, and $\triangle$ CalfP. Adiposity markers were adjusted by (Model 1) $\Delta W C$ non-adjusted model, (Model 2) $\Delta W C$ adjusted by $\Delta T_{S F}$ (Model 3) $\Delta W C$ adjusted by $\Delta T_{S F}$ and $\Delta S E_{S F}$ (Model 4) $\Delta W C$ adjusted by $\Delta T_{S F} \Delta S E_{S F}$ and $\Delta / C_{S F}$ and (Model 5) $\Delta W C$ adjusted by $\Delta T_{S F} \Delta S E_{S F} \Delta / C_{S G}$ and $\Delta$ Calf $T_{S F}$ Bold values denote significant associations at $p<0.05$ by different linear regression models; Pearson $r$ test ( $r$.

such as WC or subcutaneous fat decreases, as previously reported in IR cohorts. Other anthropometric effects on metabolic health are shown for example after 14-weeks of a) exercise plus weight loss or b) exercise without weight loss that led to a reduction in both $\Delta \mathrm{FPG}-5.8$ and $-1.5 \mathrm{mg} / \mathrm{dl}$, and $\Delta \mathrm{FI}-44.4$ and $-13.7 \%$, respectively, in each strategy (Ross et al., 2004). However, considering the increases in SMM in RT and CT, but also the higher decreases in adiposity (i.e., WC and subcutaneous fat) markers after HIIT, it is possible to presume that the residual effect and thus their prolonged beneficial effects of exercise on glucose control in FPG can be highly dependent more on fat reduction than SMM increases post-exercise cessation. In brief, part of these presumptions has been previously described in the physiopathology of the IR (Abdul-Ghani and DeFronzo, 2010), and the athlete paradox, which is relevant to this exercise intervention in our IR cohort (Goodpaster et al., 2001). Following this, exercise training could decrease both adiposity markers as can be seen in Table 1 and Figure 5, and potentially also at intramyocellular content as previously (Dube et al., 2008), and thus indirectly prolong insulin sensitivity from the last exercise cession in both HIIT and RT.

The possibility of "interference effects" from CT adaptations has been proposed from the combination of RT (i.e., increased SMM and bone mass) or moderate-intensity CT (i.e., decrease 
in body fat markers) regimens, in contrast to the individual application of RT and moderate-intensity CT (Wilson et al., 2012; Lundberg et al., 2013; Fyfe et al., 2014). However, our data reveal that $\mathrm{CT}$ promoted a remarkable metabolic beneficial effect. Indeed, 12-weeks of CT modified FPG; however, this improvement was rapidly lost at 72 -h post-training, increasing $\Delta \mathrm{FPG}_{72 \mathrm{~h}}(\Delta$ $+6.6 \mathrm{mg} / \mathrm{dl}$ ). Based on these results, CT exercise appears to be the intervention that most rapidly loses its acquired benefits posttraining compared with the HIIT and RT regimens, showing the poorest residual capacity to maintain FPG from $24 \mathrm{~h}$ to post-72h of exercise cessation. There is evidence that CT could compromise the adaptations induced by each HIIT and RT alone (Fyfe et al., 2014; Coffey and Hawley, 2017); it consists in that signaling responses mitochondrial biogenesis adaptations [i.e., adenosine monophosphate (AMP)-activated protein kinase (AMPK), Ca2+/calmodulin-dependent kinase II, and peroxisome proliferator-activated receptor-c coactivator-1] seem to diminish the muscle anabolic pathways activated by RT [i.e., mechanistic target of rapamycin complex 1 (mTORC1)] and downstream effectors the $70 \mathrm{kDa}$ ribosomal S6 protein kinase $(\mathrm{S} 6 \mathrm{~K})$ and eukaryotic initiation factor $4 \mathrm{E}$ binding protein (4E-BP1; Ronnestad et al., 2012; Jones et al., 2016; Coffey and Hawley, 2017), and although we do not measure these molecular proteins, but apparently, it seems not at this moment to affect the metabolic and cardiovascular adaptations from CT (Álvarez et al., 2019; Delgado-Floody et al., 2020, 2021).

Training volume (quantity) has been proposed as one of the principles of training along with quality (intensity; Da Silva et al., 2020) and offers a possible explanation for our results. Our study used low frequency and volume training for RT and HIIT modalities, in contrast to the higher frequency and volume training for the CT modality (RT group: two sessions/week, $80 \mathrm{~min} /$ week; HIIT group: three sessions/week, $60 \mathrm{~min} /$ week; and CT group: three sessions/week, $180 \mathrm{~min} /$ week). It is therefore difficult to speculate on the possible mechanisms for the low maintenance (i.e., low residual capacity) of $\mathrm{FPG}_{72 \mathrm{~h}}$ in the $\mathrm{CT}$ intervention. The physiological effects of CT (combining RT and HIIT in this specific order) were then presumably neither synergic nor additive, as was shown by worsened in FPG from $24 \mathrm{~h}$ to $72 \mathrm{~h}(+6.6 \mathrm{mg} /$ dl). Moreover, we observed relative maintenance of both FPG and FI at $72 \mathrm{~h}$ after the RT cessation but not after the combination with HIIT in CT. For example, Tokmakidis et al. (2014) reported that 9 months of CT resulted in an $\triangle \mathrm{FPG}-12 \%$ in patients with T2DM, whereas this outcome was increased slightly $(+0.7 \%)$ 3 months after exercise cessation; however, improvements in glycosylated hemoglobin were promoted by 9 months of CT were completely reversed after 3 months of physical inactivity. This information can also suggest that metabolic adaptations following a period of physical training are critically dependent on being regular and consistent.

Considering that CT is a combination of RT and HIIT, our data revealed that exercise adaptation for secondary endpoints of adiposity markers, the results for $\mathrm{WC}, \mathrm{T}_{\mathrm{SF}}, \mathrm{SE}_{\mathrm{SF}}, \mathrm{IC}_{\mathrm{SF}}$, and Calf $\mathrm{SF}$ revealed that HIIT alone showed greater effect sizes for improving (i.e., decreasing) these markers, followed by RT, whereas CT showed the lowest effect size for these outcomes (Figure 5). The role of HIIT in stimulating molecular mechanisms that improve fat oxidation is well established (Astorino and Schubert, 2018), and catecholamines are highly activated after intermittent exercise, such as HIIT (Boutcher, 2011). Thus, one may speculate that additionally to those adiposity markers that were decreased postexercise, other potential mechanisms underlying the residual effects post-HIIT and RT at least can be related with those acute hormonal roles from post-exercise cessation (Boutcher, 2011) that mediate some of the post-exercise glucose control improvements (Dube et al., 2011). These results of improving adiposity markers in HIIT and RT were displayed despite the higher energy expenditures

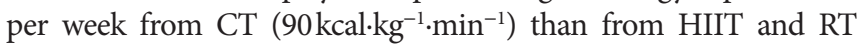
$\left(\sim 45 \mathrm{kcal} \cdot \mathrm{kg}^{-1} \cdot \mathrm{min}^{-1}\right.$ per session). However, it is well known that improvements in oxidative metabolism (i.e., decreases of carbohydrate oxidation and increases in fat oxidation during exercise) after $\sim 10 \mathrm{~min}$ of HIIT can be similar to $\sim 40-60 \mathrm{~min}$ of MICT (Burgomaster et al., 2008).

Concerning predict the residual effects of $\mathrm{CT}$ at $\Delta \mathrm{FPG}_{72 \mathrm{~h}}$ and $\Delta \mathrm{FI}_{72 \mathrm{~h}}$ by anthropometric/body composition or adiposity, stronger associations were found for body composition/anthropometry outcomes (model 4) with $\Delta \mathrm{FPG}_{72 \mathrm{~h}}$ (Table 2) and with $\Delta \mathrm{FI}_{72 \mathrm{~h}}$ (model 5; Table 3). Thus, as $\triangle \mathrm{FPG}_{72 \mathrm{~h}}$ was increased in the $\mathrm{CT}$ group with a larger effect size $\left(+6.6 \mathrm{mg} / \mathrm{dl}, \eta^{2}: 0.76\right.$, Figure $\left.3 \mathrm{G}\right)$, and the $\Delta \mathrm{FI}_{72 \mathrm{~h}}$ showed no real change, we presume that the residual effects for FPG and FI after 72-h post-training cessation are more related to body composition outcomes (i.e., decreases at adiposity outcomes) than increases at SMM that was also shown in both RT and CT groups (Figure 4A). Additionally, the $\triangle \mathrm{FPG}_{72 \mathrm{~h}}$ was significantly different to CG, as well as HIIT, and RT, but only the CT results showed a larger effect size, revealing the magnitude of difference to loss the residual effects from HIIT or RT alone, than by CT. As expected, the RT group showed significantly improved anthropometric parameters, whereas a significant loss of adipose tissue was mainly observed in the HIIT group. Accordingly, our data reveal that the metabolic adaptations after CT then can be explained by RT and HIIT, independently. However, considering that there may be an interference effect promoted by RT and HIIT, future studies of the cellular and molecular mechanisms might help to explain in part the mechanisms underlying the residual effects of RT and HIIT exercises on CT adaptations.

Our study presents some strengths that are important to highlight, such as (i) we used FPG, FI, and HOMA-IR indices, which are frequently used in the public health setting; (ii) we report RT and HIIT adaptations related to anthropometric/body composition outcomes regularly used in exercise training interventions; and (iii) the residual effects after CT training were not sufficient to improve the metabolic outcome in insulin-resistant patients. Our study is not without its limitations. For example, there was a lack of dietary control during the intervention, especially during the $24 \mathrm{~h}$ to $72 \mathrm{~h}$ in which metabolic outcomes were studied at preand post-test; however, the participants were reminded to maintain their current lifestyle habits. During the CT intervention, we first applied the RT component and then the HIIT exercises, and it is known that there is a potential interaction in the effects of exercise according to their order in the session. The sessions per week were different (HIIT 3, RT 2, and CT 3s/wk); however, these were displayed following international exercise 
recommendations per week (Bull et al., 2020). Also, the recovery period was different between HIIT and RT; however, the cardiorespiratory demands are higher in HIIT, with a need to re-establish the muscle and cardiorespiratory capacity using a double recovery period time. We also acknowledge that there are issues with the study design related to women's reproductive health since we did not control for the menstrual cycle phase when performing pre-post testing, nor did we stratify groups by menopausal status. Also, assuming that participants maintained their energy intake patterns during the 72 -h post-testing retention period, the CT group would have nearly twice as much energy excess compared to the RT or HIIT groups since the CT group expended more energy in the exercise sessions. This excess energy intake may explain part of the worsened FPG results in the CT group. Future studies could randomly assign the order of the intervention to avoid bias, include more sample size, to increase the control of the energy expenditure similarly at pre- and post-exercise cessation conditions, and to apply more than FPG the oral glucose tolerance test in which peripheral tissues key for glucose control as skeletal muscle mass is key more than FPG in which is the liver this role. Lastly, we did not perform any cellular and molecular analysis, which would improve the interpretation of our data and reveal potential mechanisms for more explanations.

\section{CONCLUSION}

In summary, our results reveal that in insulin-resistant women HIIT decreases FPG, RT decreases FI 24-h post-training, and both types of exercise interventions when performed independently have a noteworthy residual effect on FPG and FI (post-72h) when compared with the CT intervention. However, it would be necessary to increase the residual effect study with larger sample sizes in clinical cohorts.

\section{DATA AVAILABILITY STATEMENT}

The original contributions presented in the study are included in the article/supplementary material, and further inquiries can be directed to the corresponding author.

\section{REFERENCES}

Abdul-Ghani, M. A., and Defronzo, R. A. (2010). Pathogenesis of insulin resistance in skeletal muscle. J. Biomed. Biotechnol. 2010, 1-19. doi: $10.1155 / 2010 / 476279$

Álvarez, C., Ramírez, R., Flores, M., Zúñiga, C. Y., and Celis-Morales, C. A. (2012). Efectos del ejercicio físico de alta intensidad y sobrecarga en parámetros de salud metabólica en mujeres sedentarias, pre-diabéticas con sobrepeso u obesidad. Rev. Med. Chil. 140, 1289-1296. doi: 10.4067/S003498872012001000008

Álvarez, C., Ramírez-Campillo, R., Lucia, A., Ramírez-Vélez, R., and Izquierdo, M. (2019). Concurrent exercise training on hyperglycemia and comorbidities associated: non-responders using clinical cutoff points. Scand. J. Med. Sci. Sports 29, 952-967. doi: 10.1111/sms.13413

Alvarez, C., Ramirez-Campillo, R., Martinez-Salazar, C., Mancilla, R., Flores-Opazo, M., Cano-Montoya, J., et al. (2016). Low-volume high-intensity interval training as a therapy for type 2 diabetes. Int. J. Sports Med. 37, 723-729. doi: 10.1055/s-0042-104935

\section{ETHICS STATEMENT}

The studies involving human participants were reviewed and approved by the Family Healthcare Center Tomas Rojas Vergara (TRV) of Los Lagos, Chile (no. 0204015). The patients/participants provided their written informed consent to participate in this study. Written informed consent was obtained from the individual(s) for the publication of any potentially identifiable images or data included in this article.

\section{AUTHOR CONTRIBUTIONS}

CA, EC, GG, DA, and MI: conceptualization and visualization. CA, EC, GG, DA, MM-A, PD-F, and MI: methodology. CA, DA, MM-A, PD-F, and MI: software. CA, EC, MM-A, AA-M, and MI: validation. CA, EC, GG, DA, MM-A, and MI: formal analysis. CA, EC, GG, DA, MM-A, PD-F, FF, AA-M, and MI: investigation and writing-review and editing. CA: data curation and project administration. CA, EC, GG, and MI: writingoriginal draft preparation and supervision. CA, EC, and MI: funding acquisition. All authors have read and agreed to the published version of the manuscript.

\section{FUNDING}

CA was funded partially by privates. MI was funded by a research grant PI17/01814 of the Ministerio de Economía, Industria y Competitividad (ISCIII, FEDER). EGC was funded by Conselho Nacional de Desenvolvimento Científico e Tecnológico (CNPq \#303399/2018-0) during this project.

\section{ACKNOWLEDGMENTS}

We would like to thank the volunteers who participated in our study. Also, the authors thank Silvana Cartagena Quinteros for their help in correcting the language of our manuscript.

American Diabetes Association (2017). 2. Classification and diagnosis of diabetes. Diabetes Care 40, S11-S24. doi: 10.2337/dc17-S005

Andersen, E., and Høstmark, A. T. (2007). Effect of a single bout of resistance exercise on postprandial glucose and insulin response the next day in healthy, strength-trained men. J. Strength Cond. Res. 21, 487-491. doi: 10.1519/R20105.1

Astorino, T. A., and Schubert, M. M. (2018). Changes in fat oxidation in response to various regimes of high intensity interval training (HIIT). Eur. J. Appl. Physiol. 118, 51-63. doi: 10.1007/s00421-017-3756-0

Bagheri, R., Moghadam, B. H., Church, D. D., Tinsley, G. M., Eskandari, M., Moghadam, B. H., et al. (2020). The effects of concurrent training order on body composition and serum concentrations of follistatin, myostatin and GDF11 in sarcopenic elderly men. Exp. Gerontol. 133:110869. doi: 10.1016/j.exger.2020.110869

Bajpeyi, S., Tanner, C. J., Slentz, C. A., Duscha, B. D., Mccartney, J. S., Hickner, R. C., et al. (2009). Effect of exercise intensity and volume on persistence of insulin sensitivity during training cessation. J. Appl. Physiol. 106, 1079-1085. doi: 10.1152/japplphysiol.91262.2008 
Boutcher, S. H. (2011). High-intensity intermittent exercise and fat loss. J. Obes. 2011, 1-10. doi: 10.1155/2011/868305

Brooks, N., Layne, J. E., Gordon, P. L., Roubenoff, R., Nelson, M. E., and Castaneda-Sceppa, C. (2007). Strength training improves muscle quality and insulin sensitivity in Hispanic older adults with type 2 diabetes. Int. J. Med. Sci. 4, 19-27. doi: 10.7150/ijms.4.19

Bull, F. C., Al-Ansari, S. S., Biddle, S., Borodulin, K., Buman, M. P., Cardon, G., et al. (2020). World Health Organization 2020 guidelines on physical activity and sedentary behaviour. Br. J. Sports Med. 54, 1451-1462. doi: 10.1136/ bjsports-2020-102955

Burgomaster, K. A., Howarth, K. R., Phillips, S. M., Rakobowchuk, M., Macdonald, M. J., Mcgee, S. L., et al. (2008). Similar metabolic adaptations during exercise after low volume sprint interval and traditional endurance training in humans. J. Physiol. 586, 151-160. doi: 10.1113/jphysiol.2007.142109

Burke, L. M., Van Loon, L. J., and Hawley, J. A. (2017). Postexercise muscle glycogen resynthesis in humans. J. Appl. Physiol. 122, 1055-1067. doi: 10.1152/ japplphysiol.00860.2016

Coffey, V. G., and Hawley, J. A. (2017). Concurrent exercise training: do opposites distract? J. Physiol. 595, 2883-2896. doi: 10.1113/JP272270

Colberg, S. R. (2017). Key points from the updated guidelines on exercise and diabetes. Front. Endocrinol. 8:33. doi: 10.3389/fendo.2017.00033

Colberg, S. R., Sigal, R. J., Yardley, J. E., Riddell, M. C., Dunstan, D. W., Dempsey, P. C., et al. (2016). Physical activity/exercise and diabetes: a position statement of the American Diabetes Association. Diabetes Care 39, 2065-2079. doi: $10.2337 / \mathrm{dc} 16-1728$

Da Silva, M. A. R., Baptista, L. C., Neves, R. S., De França, E., Loureiro, H., Lira, F. S., et al. (2020). The effects of concurrent training combining both resistance exercise and high-intensity interval training or moderate-intensity continuous training on metabolic syndrome. Front. Physiol. 11:572. doi: 10.3389/fphys.2020.00572

Declaration of Helsinki (2013). World Medical Association Declaration of Helsinki Ethical Principles for Medical Research Involving Human Subjects. Available at: https://jamanetwork.com/journals/jama/fullarticle/1760318.

Del Vecchio, F. B., Coswig, V. S., Cabistany, L. D., Orcy, R. B., and Gentil, P. (2020). Effects of exercise cessation on adipose tissue physiological markers related to fat regain: A systematic review. SAGE Open Med. 8:205031212093695. doi: $10.1177 / 2050312120936956$

Delgado-Floody, P., Latorre-Román, P. Á., Jerez-Mayorga, D., Caamaño-Navarrete, F., Cano-Montoya, J., Laredo-Aguilera, J. A., et al. (2020). Poor sleep quality decreases concurrent training benefits in markers of metabolic syndrome and quality of life of morbidly obese patients. Int. J. Environ. Res. Public Health 17:6804. doi: 10.3390/ijerph17186804

Delgado-Floody, P., Soriano-Maldonado, A., Rodríguez Pérez, M. A., Latorre-Román, P. Á., Martínez-Salazar, C., Vargas, C. A., et al. (2021). The effects of two different orders of concurrent training on the interindividual variability of health markers of metabolic syndrome and fitness in severe/ morbidly obesity women. A randomized control trial. Front. Physiol. 12:1160. doi: $10.3389 /$ fphys.2021.694798

Dube, J. J., Amati, F., Stefanovic-Racic, M., Toledo, F. G. S., Sauers, S. E., and Goodpaster, B. H. (2008). Exercise-induced alterations in intramyocellular lipids and insulin resistance: the athlete's paradox revisited. Am. J. Physiol. Endocrinol. Metab. 294, E882-E888. doi: 10.1152/ajpendo.00769.2007

Dube, J., Amati, F., Toledo, F., Stefanovic-Racic, M., Rossi, A., Coen, P., et al. (2011). Effects of weight loss and exercise on insulin resistance, and intramyocellular triacylglycerol, diacylglycerol and ceramide. Diabetologia 54, 1147-1156. doi: 10.1007/s00125-011-2065-0

Dunstan, D. W., Daly, R. M., Owen, N., Jolley, D., De Courten, M., Shaw, J., et al. (2002). High-intensity resistance training improves Glycemic control in older patients With type 2 diabetes. Diabetes Care 25, 1729-1736. doi: 10.2337/diacare.25.10.1729

Dykes, P., Francis, A., and Marks, R. (1976). Measurement of dermal thickness with the Harpenden skinfold caliper. Arch. Dermatol. Res. 256, 261-263. doi: 10.1007/BF00572491

Fyfe, J. J., Bishop, D. J., and Stepto, N. K. (2014). Interference between concurrent resistance and endurance exercise: molecular bases and the role of individual training variables. Sports Med. 44, 743-762. doi: 10.1007/s40279-0140162-1

Garmendia, M. L., Lera, L., Sánchez, H., Uauy, R., and Albala, C. (2009). Valores normativos de resistencia a la insulina mediante HOMA-IR en adultos mayores de Santiago de Chile. Rev. Med. Chil. 137, 1409-1416. doi: 10.4067/S0034-98872009001100001

Gillen, J. B., Percival, M. E., Ludzki, A., Tarnopolsky, M. A., and Gibala, M. J. (2013). Interval training in the fed or fasted state improves body composition and muscle oxidative capacity in overweight women. Obesity 21, 2249-2255. doi: $10.1002 /$ oby.20379

Glowacki, S. P., Martin, S. E., Maurer, A., Baek, W., Green, J. S., and Crouse, S. F. (2004). Effects of resistance, endurance, and concurrent exercise on training outcomes in men. Med. Sci. Sports Exerc. 36, 2119-2127. doi: 10.1249/01. mss.0000147629.74832.52

Goodpaster, B. H., He, J., Watkins, S., and Kelley, D. E. (2001). Skeletal muscle lipid content and insulin resistance: evidence for a paradox in endurancetrained athletes. J. Clin. Endocrinol. Metab. 86, 5755-5761. doi: 10.1210/ jcem.86.12.8075

Goulet, E. D., Melancon, M. O., Aubertin-Leheudre, M., and Dionne, I. J. (2005). Aerobic training improves insulin sensitivity $72-120 \mathrm{~h}$ after the last exercise session in younger but not in older women. Eur. J. Appl. Physiol. 95, 146-152. doi: 10.1007/s00421-005-1403-7

Hayes, S. C., Spence, R. R., Galvao, D. A., and Newton, R. U. (2009). Australian Association for Exercise and Sport Science position stand: optimising cancer outcomes through exercise. J. Sci. Med. Sport 12, 428-434. doi: 10.1016/j. jsams.2009.03.002

Jelleyman, C., Yates, T., O'donovan, G., Gray, L., King, J. A., Khunti, K., et al. (2015). The effects of high-intensity interval training on glucose regulation and insulin resistance: a meta-analysis. Obes. Rev. 16, 942-961. doi: 10.1111/ obr.12317

Jenkins, N., and Hagberg, J. M. (2011). Aerobic training effects on glucose tolerance in Prediabetic and Normoglycemic humans. Med. Sci. Sports Exerc. 43, 2231-2240. doi: 10.1249/MSS.0b013e318223b5f9

Jones, T. W., Walshe, I. H., Hamilton, D. L., Howatson, G., Russell, M., Price, O. J., et al. (2016). Signaling responses After varying sequencing of strength and endurance training in a fed state. Int. J. Sports Physiol. Perform. 11, 868-875. doi: $10.1123 /$ ijspp.2015-0534

Karvonen, J., and Vuorimaa, T. (1988). Heart rate and exercise intensity during sports activities. Practical application. Sports Med. 5, 303-311. doi: 10.2165/00007256-198805050-00002

Lakens, D. (2013). Calculating and reporting effect sizes to facilitate cumulative science: a practical primer for t-tests and ANOVAs. Front. Psychol. 4:863. doi: 10.3389 /fpsyg.2013.00863

Little, J. P., Gillen, J. B., Percival, M. E., Safdar, A., Tarnopolsky, M. A., Punthakee, Z., et al. (2011). Low-volume high-intensity interval training reduces hyperglycemia and increases muscle mitochondrial capacity in patients with type 2 diabetes. J. Appl. Physiol. 111, 1554-1560. doi: 10.1152/ japplphysiol.00921.2011

Little, J.P., Karstoft, K., and Safdar, A. (2018). Optimizing Exercise for the Prevention and Treatment of Type 2 Diabetes. Lausanne: Frontiers Media SA.

Lundberg, T. R., Fernandez-Gonzalo, R., Gustafsson, T., and Tesch, P. A. (2013). Aerobic exercise does not compromise muscle hypertrophy response to short-term resistance training. J. Appl. Physiol. 114, 81-89. doi: 10.1152/ japplphysiol.01013.2012

Marcus, R. L., Addison, O., Lastayo, P. C., Hungerford, R., Wende, A. R., Hoffman, J. M., et al. (2013). Regional muscle glucose uptake remains elevated one week after cessation of resistance training independent of altered insulin sensitivity response in older adults with type 2 diabetes. J. Endocrinol. Investig. 36, 111-117. doi: 10.3275/8333

Matos, M. A. D., Vieira, D. V., Pinhal, K. C., Lopes, J. F., Dias-Peixoto, M. F., Pauli, J. R., et al. (2018). High-intensity interval training improves markers of oxidative metabolism in skeletal muscle of individuals with obesity and insulin resistance. Front. Physiol. 9:1451. doi: 10.3389/fphys.2018. 01451

Matthews, D. R., Hosker, J. P., Rudenski, A. S., Naylor, B. A., Treacher, D. F., and Turner, R. C. (1985). Homeostasis model assessment: insulin resistance and beta-cell function from fasting plasma glucose and insulin concentrations in man. Diabetologia 28, 412-419. doi: 10.1007/BF0028 0883

O’Donovan, G., Blazevich, A. J., Boreham, C., Cooper, A. R., Crank, H., Ekelund, U., et al. (2010). The ABC of physical activity for health: a consensus statement from the British Association of Sport and Exercise Sciences. J. Sports Sci. 28, 573-591. doi: 10.1080/02640411003671212 
Richter, E. A., Hansen, B. F., and Hansen, S. A. (1988). Glucose-induced insulin resistance of skeletal-muscle glucose transport and uptake. Biochem. J. 252, 733-737. doi: 10.1042/bj2520733

Ronnestad, B. R., Hansen, E. A., and Raastad, T. (2012). High volume of endurance training impairs adaptations to 12 weeks of strength training in well-trained endurance athletes. Eur. J. Appl. Physiol. 112, 1457-1466. doi: 10.1007/s00421-011-2112-z

Ross, R., Janssen, I., Dawson, J., Kungl, A. M., Kuk, J. L., Wong, S. L., et al. (2004). Exercise-induced reduction in obesity and insulin resistance in women: a randomized controlled trial. Obes. Res. 12, 789-798. doi: 10.1038/ oby. 2004.95

Ross, L. M., Slentz, C. A., Zidek, A. M., Huffman, K. M., Shalaurova, I., Otvos, J. D., et al. (2021). Effects of amount, intensity, and mode of exercise training on insulin resistance and type 2 diabetes risk in the STRRIDE randomized trials. Front. Physiol. 12:67. doi: 10.3389/ fphys.2021.626142

Short, K. R., Pratt, L. V., and Teague, A. M. (2012). The acute and residual effect of a single exercise session on meal glucose tolerance in sedentary young adults. J. Nutr. Metab. 2012, 1-9. doi: 10.1155/2012/278678

Slentz, C. A., Bateman, L. A., Willis, L. H., Shields, A. T., Tanner, C. J., Piner, L. W., et al. (2011). Effects of aerobic vs. resistance training on visceral and liver fat stores, liver enzymes, and insulin resistance by HOMA in overweight adults from STRRIDE AT/RT. Am. J. Physiol. Endocrinol. Metab. 301, E1033-E1039. doi: 10.1152/ajpendo.00291.2011

Timmons, J. F., Minnock, D., Hone, M., Cogan, K. E., Murphy, J. C., and Egan, B. (2018). Comparison of time-matched aerobic, resistance, or concurrent exercise training in older adults. Scand. J. Med. Sci. Sports 28, 2272-2283. doi: $10.1111 / \mathrm{sms} .13254$

Tokmakidis, S., Touvra, A.-M., Douda, H., Smilios, I., Kotsa, K., and Volaklis, K. (2014). Training, detraining, and retraining effects on glycemic control and physical fitness in women with type 2 diabetes. Horm. Metab. Res. 46, 974-979. doi: 10.1055/s-0034-1390483

Vechin, F. C., Conceição, M. S., Telles, G. D., Libardi, C. A., and Ugrinowitsch, C. (2021). Interference phenomenon with concurrent strength and high-intensity interval training-based aerobic training: An updated model. Sports Med. 51, 599-605. doi: 10.1007/s40279-020-01421-6
Villareal, D. T., Aguirre, L., Gurney, A. B., Waters, D. L., Sinacore, D. R., Colombo, E., et al. (2017). Aerobic or resistance exercise, or Both, in dieting obese older adults. N. Engl. J. Med. 376, 1943-1955. doi: 10.1056/NEJMoa1616338

Vukovich, M. D., Arciero, P. J., Kohrt, W. M., Racette, S. B., Hansen, P. A., and Holloszy, J. O. (1996). Changes in insulin action and GLUT-4 with 6 days of inactivity in endurance runners. J. Appl. Physiol. 80, 240-244. doi: 10.1152/jappl.1996.80.1.240

Wang, G., Zhou, X., Zhuo, X., and Zhang, P. (2017). Annual total medical expenditures associated with hypertension by diabetes status in US adults. Am. J. Prev. Med. 53, S182-S189. doi: 10.1016/j.amepre.2017.07.018

Wilson, J. M., Marin, P. J., Rhea, M. R., Wilson, S. M., Loenneke, J. P., and Anderson, J. C. (2012). Concurrent training: a meta-analysis examining interference of aerobic and resistance exercises. J. Strength Cond. Res. 26, 2293-2307. doi: 10.1519/JSC.0b013e31823a3e2d

Wood, R. J., and O'neill, E. C. (2012). Resistance training in type II diabetes mellitus: impact on areas of metabolic dysfunction in skeletal muscle and potential impact on bone. J. Nutr. Metab. 2012, 1-13. doi: 10.1155/2012/268197

Conflict of Interest: The authors declare that the research was conducted in the absence of any commercial or financial relationships that could be construed as a potential conflict of interest.

Publisher's Note: All claims expressed in this article are solely those of the authors and do not necessarily represent those of their affiliated organizations, or those of the publisher, the editors and the reviewers. Any product that may be evaluated in this article, or claim that may be made by its manufacturer, is not guaranteed or endorsed by the publisher.

Copyright (C) 2021 Alvarez, Ciolac, Guimarães, Andrade, Vasquez-Muñoz, MonsalvesÁlvarez, Delgado-Floody, Alonso-Martínez and Izquierdo. This is an open-access article distributed under the terms of the Creative Commons Attribution License (CC BY). The use, distribution or reproduction in other forums is permitted, provided the original author(s) and the copyright owner(s) are credited and that the original publication in this journal is cited, in accordance with accepted academic practice. No use, distribution or reproduction is permitted which does not comply with these terms. 